OPEN ACCESS

Edited by:

Claire Terry,

Corteva Agriscience ${ }^{\mathrm{TM}}$, United States

Reviewed by:

Hilmi Orhan,

Ege University, Turkey

Satyanarayana "Satya" Achanta, Duke University, United States

*Correspondence:

Karsta Luettich

Karsta.Luettich@pmi.com

Specialty section:

This article was submitted to In Vitro Toxicology,

a section of the journal

Frontiers in Toxicology

Received: 30 July 2021 Accepted: 11 November 2021 Published: 14 December 2021

Citation:

Luettich K, Sharma M,

Yepiskoposyan $\mathrm{H}$, Breheny $\mathrm{D}$ and Lowe FJ (2021) An Adverse Outcome Pathway for Decreased Lung Function Focusing on Mechanisms of Impaired Mucociliary Clearance Following

Inhalation Exposure.

Front. Toxicology. 3:750254. doi: 10.3389/ftox.2021.750254

\section{An Adverse Outcome Pathway for Decreased Lung Function Focusing on Mechanisms of Impaired Mucociliary Clearance Following Inhalation Exposure}

\author{
Karsta Luettich ${ }^{1 *}$, Monita Sharma ${ }^{2}$, Hasmik Yepiskoposyan ${ }^{1}$, Damien Breheny ${ }^{3}$ and \\ Frazer J. Lowe ${ }^{4}$ \\ ${ }^{1}$ Philip Morris International R\&D, Philip Morris Products S.A., Neuchatel, Switzerland, ${ }^{2}$ PETA Science Consortium International \\ e.V., Stuttgart, Germany, ${ }^{3}$ British American Tobacco (Investments) Ltd., Group Research and Development, Southampton, \\ United Kingdom, ${ }^{4}$ Broughton Nicotine Services, Earby, Lancashire, United Kingdom
}

Adverse outcome pathways (AOPs) help to organize available mechanistic information related to an adverse outcome into key events (KEs) spanning all organizational levels of a biological system(s). AOPs, therefore, aid in the biological understanding of a particular pathogenesis and also help with linking exposures to eventual toxic effects. In the regulatory context, knowledge of disease mechanisms can help design testing strategies using in vitro methods that can measure or predict KEs relevant to the biological effect of interest. The AOP described here evaluates the major processes known to be involved in regulating efficient mucociliary clearance (MCC) following exposures causing oxidative stress. MCC is a key aspect of the innate immune defense against airborne pathogens and inhaled chemicals and is governed by the concerted action of its functional components, the cilia and airway surface liquid (ASL). The AOP network described here consists of sequences of KEs that culminate in the modulation of ciliary beat frequency and ASL height as well as mucus viscosity and hence, impairment of MCC, which in turn leads to decreased lung function.

Keywords: adverse outcome pathway, AOP, mucociliary clearance, ciliary beat frequency, lung function, new approach methodologies, NAMs, inhalation toxicity

\section{INTRODUCTION}

Regulatory frameworks are moving towards risk assessment approaches that better protect human health and are not reliant on testing in animals. Therefore, 21 st century science is incorporating the use of human-relevant methods that are ethical, scientifically sound, and can accurately predict the toxicity of chemicals. In silico models that consider human-relevant parameters as well as in vitro methods that vary in complexity-spanning from mono-to co-culture systems-are already being used to predict human outcomes. For example, the Organisation for Economic Co-operation and Development (OECD) (OECD, 2021) uses combined information from several sources (e.g. in silico predictions, in chemico, in vitro data) to predict pathological outcomes in humans in response to chemical exposure. Anchored to known mechanisms of human toxicity such mechanism-based 
approaches enable us to understand whether a chemical will be toxic and through which pathway(s) it may act to cause the adverse outcome (AO) (Clippinger et al., 2018).

Adverse outcome pathways (AOP) are a means to organize known information related to a pathological outcome and understand the mechanism leading to the adverse effect. Starting with a molecular initiating event (MIE) and ending in an $\mathrm{AO}, \mathrm{AOPs}$ are a sequence of causally linked key events (KE) that span different levels of biological organization-from the molecular to the whole organism level (Ankley et al., 2010). An AOP may not necessarily include every single event that contributes to the development of the $\mathrm{AO}$, but it does include all KEs that are critical for its development (OECD, 2017). In vitro and in silico assays that measure each of the KEs of an AOP can be used to design testing approaches that closely predict human responses and replace the need for in vivo data in order to derive benchmark values for determining the potential adverse health impacts of chemicals. When combined with existing data and physicochemical information related to the test substance, AOPbased testing can help develop integrated approaches that can predict human responses (OECD, 2021). Given the usefulness of AOPs in the risk assessment of chemicals, the OECD launched a program for the development of AOPs in 2012; called the AOPWiki, this program is overseen by the Extended Advisory Group on Molecular Screening and Toxicogenomics (EAGMST). Several online resources, including the OECD AOP users' handbook, are available to aid developers in compiling AOPs on the AOPwiki (OECD, 2018). There are currently more than 300 AOPs online, at various stages of completion. One of these is AOP148 [EGFR Activation Leading to Decreased Lung Function, https://aopwiki. org/aops/148], which is extended and complemented by the AOP network described here.

With a surface area of $\sim 100 \mathrm{~m}^{2}$ and ventilated by 10,000 to 20,000 L of air per day (National Research Council, 1988; Frohlich et al., 2016), the lungs are a major barrier that protect the body from a host of external factors that enter the respiratory system and may cause lung pathologies. Mucociliary clearance (MCC) is a key aspect of the innate immune defense against airborne pathogens and inhaled particles. MCC is governed by the concerted action of its functional components, the cilia and the airway surface liquid (ASL), where the latter comprises mucus and the periciliary layer (PCL) (Bustamante-Marin and Ostrowski, 2017). Healthy subjects produce $>10 \mathrm{ml}$ airway secretions daily (King, 2006), which are continuously transported by the mucociliary escalator. Disturbances in any of the processes that regulate ASL volume, mucus production, mucus viscoelastic properties, or ciliary function can cause MCC dysfunction and are linked to airway diseases such as chronic obstructive pulmonary disease (COPD) and asthma, both of which bear a significant risk of increased morbidity and mortality. The mechanism by which exposure to inhaled toxicants might lead to mucus hypersecretion and thereby impact pulmonary function has already been mapped in AOP148 on decreased lung function. However, whether an exposure-related decline in lung function is solely related to excessive production of mucus is debatable, particularly in light of the close relationship between mucus, cilia function, and efficient MCC. To date, no single event has been attributed to MCC impairment. This AOP work evaluates the major processes known to be involved in ensuring efficient MCC and consists of sequences of KEs that culminate in the modulation of ASL, ciliary beat frequency (CBF), and mucus viscosity. Together, these processes impair MCC, which-when persistent-leads to decreased lung function. Evidence was gathered from the peer-reviewed literature from multiple sources (e.g., PubMed, Web of Science, Scopus) by keyword searches. No publication date limit was applied. Both empirical and quantitative evidence was captured, consolidated and transferred to the corresponding $\mathrm{KE}$ and KER pages on the AOPwiki following the recommendations in the AOP User's Handbook.

\section{SUMMARY OF KEY EVENTS AND MECHANISMS}

The epithelium of the respiratory tract has a powerful defense mechanism against airborne pollutants, owing to the combined performance of mucus-producing goblet cells and ciliated cells that are covered with microtubular projections called cilia. In response to various irritants and pathogens, goblet cells produce and secrete mucus, and the cilia sweep the mucus upward through coordinated beating motions, thus clearing the airways of these substances-a process which is termed MCC. Optimal MCC is dependent on multiple factors, including cilia number and structure, ASL height ${ }^{1}$, and the physical and chemical properties of mucus. Any disturbances in these factors can lead to impaired MCC. A summary schematic of the AOP network delineating processes that lead from oxidative stress to decreased lung function is presented in Figure 1 and detailed on the AOPwiki (https://aopwiki.org/aops/411, https:// aopwiki.org/aops/424, https://aopwiki.org/aops/425).The MIE for this network of AOP is oxidative stress. Oxidative stress is generally regarded as a redox imbalance characterized by the increased production of oxidative species and concurrent depletion of antioxidant defenses. Thus, the overall redox balance of the cell/tissue is tipped in favor of oxidation. Various highly reactive species, collectively referred to as "reactive oxygen species" (ROS) or "reactive nitrogen species" (RNS), are formed continuously at relatively low concentrations during the normal biochemical functioning of cells and tissues. They are highly unstable because they contain unpaired electrons capable of initiating oxidation reactions and include free radicals such as hydroxyl radicals, superoxide anions, oxygen radicals, nitric oxide, and non-free radicals, such as hydrogen peroxide, peroxynitrite and hypochlorous acid (Rahman et al., 2006). However, upon exposure to certain xenobiotics or in the presence of pathogens, cells may form excessive ROS/RNS,

\footnotetext{
${ }^{1}$ The literature interchangeably refers to ASL height, ASL volume and ASL depth. The data presented in original research articles indicate that these terms are synonymous. To simplify the presentation of evidence, we will refer to "ASL height" here.
} 


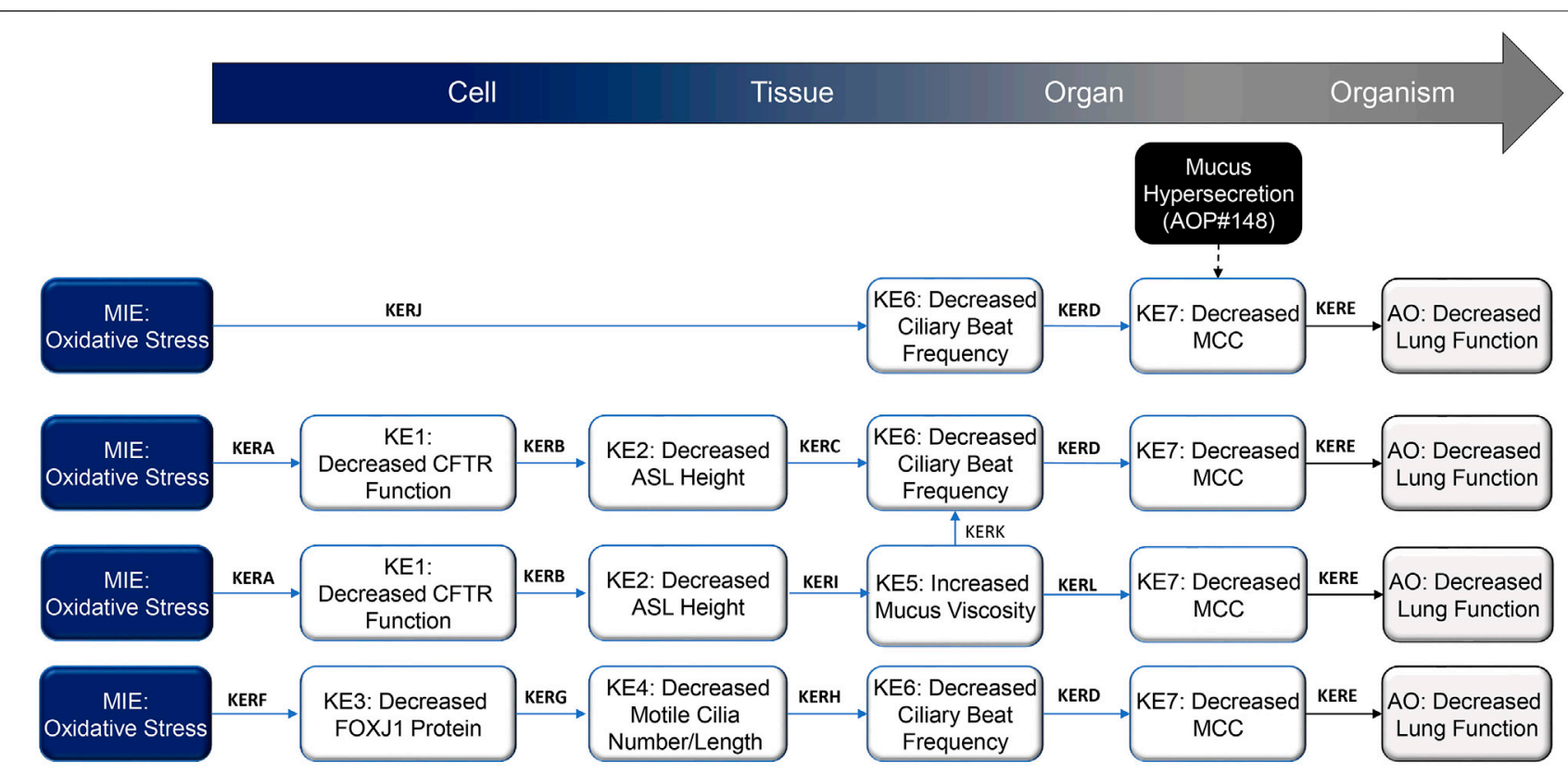

FIGURE 1 |Schematic representation of the proposed decreased lung function adverse outcome pathways (AOP), focusing on mechanisms that result in impaired mucociliary clearance (MCC) following inhalation exposure. Abbreviations: AO, adverse outcome; ASL, airway surface liquid; CFTR, cystic fibrosis transmembrane regulator; FOXJ1, forkhead box protein J1; KE, key event; KER; key event relationship; MCC, mucociliary clearance; MIE, molecular initiating event.

which may react with cellular components such as proteins, lipids and nuclear material, leading to the dysfunction of these components and, ultimately, cell death and disease manifestation (Halliwell and Aruoma, 1991; Berlett and Stadtman, 1997). Protective enzymes such as catalase, glutathione peroxidase, superoxide dismutase, and thioredoxin-in combination with radical scavengers such as glutathione, ascorbic acid, uric acid and vitamin E-work in concert to maintain ROS/RNS levels that are not overly damaging to cells and cellular systems (Rahman et al., 2006).

In the lungs, free radical species may be endogenously produced or introduced following exposure to exogenous sources, such as air pollutants, inhaled chemicals/therapeutics, and cigarette smoke (Church and Pryor, 1985). The main cellular sources of reactive species in the lungs include neutrophils, eosinophils, alveolar macrophages, alveolar epithelial cells, bronchial epithelial cells, and endothelial cells (Holland et al., 1990; Kinnula et al., 1992; Kinnula et al., 1995); these cells may increase their ROS/RNS production in response to infection or tissue damage. ROS/RNS generally inflict their effects by remodeling extracellular matrix and stimulating mucus secretion and repair responses (Poli and Parola, 1997). Oxidative stress can lead to a variety of respiratory diseases, such as asthma, acute respiratory distress syndrome and COPD (Rahman and MacNee, 1996; Chabot et al., 1998).With respect to this specific AOP, localized oxidative stress in the airways as a result of cigarette smoke exposure, for example, can cause damage to various proteins linked to the regulation of cilia function. Reduced expression of the CFTR (cystic fibrosis transmembrane conductance regulator) transcript, diminished CFTR protein levels, and altered chloride $\left(\mathrm{Cl}^{-}\right)$channel gating lead to acquired CFTR dysfunction (Clunes et al., 2012; Braun, 2014), which perturbs the height of the ASL and facilitates cilia collapse. Furthermore, oxidative damage has been reported to decrease the FOXJ1 (forkhead box protein J1) gene and protein expression, a critical protein involved in the assembly of motile cilia (Milara et al., 2012; Brekman et al., 2014; Garcia-Arcos et al., 2016; Valencia-Gattas et al., 2016; Ishikawa and Ito, 2017). Collectively, these perturbations result in decreased MCC from the upper airways.

CFTR is a multi-domain membrane protein belonging to the large family of adenine nucleotide-binding cassette transporters (Riordan, 2008). It is an integral membrane glycoprotein which functions as cyclic adenosine monophosphate (cAMP)-activated and phosphorylation-regulated $\mathrm{Cl}^{-}$channel at the apical membrane of epithelial cells (Farinha et al., 2013). In respiratory epithelia, CFTR mediates fluid and electrolyte transport, and its function is critical to ASL homeostasis. Exposure to inhaled oxidants leads to decreased CFTR gene and protein expression as well as CFTR internalization, which reduces protein presentation at the membrane and reduces or abolishes short-circuit currents (Cantin et al., 2006a; Cantin et al., 2006b; Clunes et al., 2012; Sloane et al., 2012; Rasmussen et al., 2014). Decreased CFTR expression (KE1) in airway epithelium has been observed in cystic fibrosis and after hypoxia and cigarette smoke exposure, resulting in reduced $\mathrm{Cl}^{-}$transport and, ultimately, reduced ASL depth (Alexander et al., 2012; Clunes et al., 2012; Rasmussen et al., 2014; Woodworth, 2015; Raju et al., 2016).

The ASL is a liquid layer on the apical side of the respiratory epithelium, reportedly between 5 and $100 \mu \mathrm{m}$ in depth (Widdicombe and Widdicombe, 1995). It consists of an inner aqueous PCL, which spans the length of the cilia, and an outer gel-like mucus layer. The PCL has a low viscosity and enables ciliary beating, thereby facilitating the movement of the outer 
mucus layer toward the glottis and, ultimately, its removal by cough or ingestion (Antunes and Cohen, 2007). Both ASL composition and height are considered critical for its function (Fischer and Widdicombe, 2006). Under physiological conditions, ASL composition and height are regulated through vectorial transport of electrolytes, driven by transepithelial transport and apical secretion of $\mathrm{Cl}^{-}$by (predominantly) CFTR, which results in passive water secretion and, consequently, increased ASL height. Absorption of sodium ions $\left(\mathrm{Na}^{+}\right)$on the apical side by the epithelial sodium channel $(\mathrm{ENaC})$ and its interaction with the basolateral $\mathrm{Na}^{+} / \mathrm{K}^{+}$-ATPase leads to net absorption of $\mathrm{Na}^{+}$, which in turn drives fluid absorption and therefore decreases ASL height (KE2) (Hollenhorst et al., 2011; Althaus, 2013). Impairment of CFTR or $\mathrm{ENaC}$ function can lead to the dysfunction of the other ion channel (increased CFTR activity leads to decreased ENaC activity and vice versa) (Hobbs et al., 2013; Munkholm and Mortensen, 2014), resulting in perturbation of ASL height.

The number, structure, and cohesive beating of the motile cilia lining the upper and lower respiratory tract are critical for efficient MCC. Motile cilia are microtubular organelles, 6-7 $\mu \mathrm{m}$ long and 0.2-0.3 $\mu \mathrm{m}$ in diameter (Brooks and Wallingford, 2014; Yaghi and Dolovich, 2016). They protrude from the cell surface and generate directional flow of fluid though coordinated beating. Approximately $50-80 \%$ of the human respiratory epithelium is comprised of ciliated cells; each ciliated cell is covered by more than a hundred motile cilia, which move mucus upwards (together with mucus-trapped substances) upward (Yaghi and Dolovich, 2016; Bustamante-Marin and Ostrowski, 2017). Cilia formation is initiated and coordinated by a distinct gene expression program, led by the transcription factor FOXJ1 (Brody et al., 2000; Zhou and Roy, 2015). The multiple motile cilia assembly factors MCIDAS (multiciliate differentiation and DNA synthesis associated cell cycle protein) and GMNC (geminin coiled-coil domain containing) converge in positively regulating FOXJ1 (Stubbs et al., 2012; Arbi et al., 2016; Berta et al., 2016), whereas NOTCH (Notch homolog (Drosophila))-, IL-13 (interleukin-13)- or EGF (epidermal growth factor)-triggered signaling antagonizes FOXJ1-driven multiciliogenesis (Gomperts et al., 2007; Shaykhiev et al., 2013; Gerovac et al., 2014; Gerovac and Fregien, 2016). Although various other factors are involved in multiple motile cilia assembly-including MYB (MYB protooncogene), RFX3 (regulatory factor X3), ULK4 (Unc-51 like kinase 4), Wnt signaling, and others-they mostly act upstream or in parallel to FOXJ1 (Tan et al., 2013; Choksi et al., 2014; Liu et al., 2016; Schmid et al., 2017). FOXJ1 appears to be the major factor in multiciliogenesis, whereby its activity is necessary and also sufficient for programming cells to assemble functional motile cilia (Vij et al., 2012; Zhou and Roy, 2015). It is not surprising, therefore, that a decrease in FOXJ1 levels (KE3) inhibits ciliogenesis in multiciliated cells in zebrafish and Xenopus (Stubbs et al., 2008), and knockdown of FOXJ1 results in almost complete absence of cilia in mouse epithelial cells (Chen et al., 1998; Brody et al., 2000). FOXJ1 expression also decreases in cigarette smoke extract-treated human airway epithelial cells, leading to suppression of cilia growth, which can be restored by overexpression of the protein (Brekman et al., 2014).
Because ciliated cell density and the multiple motile cilia length and number per cell correlate with $\mathrm{CBF}$-which is routinely used as a predictor of MCC efficiency (King, 2006)it follows that, if cilia numbers decrease (KE4), CBF decreases (KE6). Cohesive beating of multiple motile cilia with a specific frequency and pattern propels mucus (and trapped particles or pathogens) upwards, creating a continuous movement (Chilvers and O'Callaghan, 2000). CBF is influenced by several factors, including structural modulation in the cilia and the concentrations of the cyclic nucleotides cAMP and cGMP and intracellular calcium $\left(\mathrm{Ca}^{2+}\right)$ (Rubin, 2002). CBF also depends on the physical and chemical properties of the ASL. If ASL height decreases following, for example, exposure to cigarette smoke, the cilia cannot extend to their full height, and MCC efficiency will drop. In addition, reduced ASL height results in airway dehydration, which increases mucus viscosity (KE5) (Gheber et al., 1998; Lai et al., 2009; Fahy and Dickey, 2010). Increased mucus viscosity, in turn, decreases CBF and slows the transport of mucus on the mucociliary escalator (i.e., decreases MCC; KE7). In chronic inflammatory states, as seen (for example) in the lungs of cystic fibrosis, asthma, or COPD patients, decreased MCC can lead to mucus impaction, resulting in the formation of mucus plugs, which then in turn obstruct the airways and, consequently, lead to decreased lung function (AO) over time (Wanner et al., 1996; Szczesniak et al., 2017; Dunican et al., 2021).

\section{EMPIRICAL EVIDENCE FOR KEY EVENT RELATIONSHIPS}

Table 1 presents a summary of supporting evidence for each of the KERs in this AOP. KERs are rated as "strong", "moderate", or "weak" on the basis of empirical evidence supporting a change in an upstream KE (KEup) leading to an appropriate change in the immediate downstream KE (KEdown). Other considerations are whether KEups occur at lower doses, earlier time points, and at a higher incidence than KEdowns and if there are any inconsistences in the published data. The experimental evidence for a causal relationship between the KEup and KEdown in this AOP has been provisionally rated as "moderate" or "strong" in most cases.

Exposure to inhaled oxidants, such as cigarette smoke and ozone, leads to decreased CFTR gene and protein expression as well as CFTR internalization (KE1), thereby reducing or abolishing open probabilities, short-circuit currents and subsequently ASL height/volume (KE2) (Kulka et al., 2005; Cantin et al., 2006a; Cantin et al., 2006b; Qu et al., 2009; Clunes et al., 2012; Sloane et al., 2012; Rasmussen et al., 2014). Both reduced mRNA stability (Cantin et al., 2006a) and decreased transcription rates (Bargon et al., 1992a; Bargon et al., 1992b; Rasmussen et al., 2014) reportedly contribute to diminished CFTR mRNA expression. CFTR expression was also modulated by STAT1 (Kulka et al., 2005; Qu et al., 2009) and Nrf2 signaling (Zhang et al., 2015). Additionally, on the posttranscriptional level, CFTR function has been shown to be affected by oxidative stress (Clunes et al., 2012) and ischemia (Brézillon et al., 1997; Bodas et al., 2017). 
TABLE 1 | Empirical evidence for key event relationships (KER).

KER

KERA

Oxidative stress leading to decreased CFTR function
Defining question: Does empirical evidence support that a change in KEup leads to an appropriate change in KEdown? Does KEup occur at lower doses, earlier time points, and higher in incidence than KEdown? Inconsistencies?

High (Strong): Multiple studies showing dependent change in both events following exposure to a wide range of specific stressors. No or few critical data gaps or conflicting data

Moderate: Demonstrated dependent change in both events following exposure to a small number of stressors. Some inconsistencies with expected pattern that can be explained by various factors

Low (Weak): Limited or no studies reporting dependent change in both events following exposure to a specific stressor, and/or significant inconsistencies in empirical support across taxa and species

Strong Inducers of oxidative stress such as cigarette smoke reduced CFTR expression at both the RNA Cantin et al. (2006a); Cantin et al. (2006b); Qu et al. (2009); Rennolds et al. (2010) and protein (Cantin et al. (2006b); Qu et al. (2009); Rennolds et al. (2010); Sloane et al. (2012); Hassan et al. (2014); Rasmussen et al. (2014); Xu et al. (2015) level in vitro. CFTR protein expression was lower in the airways of smokers compared to non-smokers Dransfield et al. (2013). In some of these studies, an accompanying decrease in $\mathrm{Cl}^{-}$conductance was also observed Qu et al. (2009); Rennolds et al. (2010); Sloane et al. (2012). There are many studies that support a direct link between oxidative stress and decreased CFTR function in vitro, ex vivo, in vivo and in human subjects. Human primary epithelial cells and cell lines of respiratory epithelial origin have consistently decreased conductance of $\mathrm{Cl}^{-}$and other ions following exposure to cigarette smoke and other oxidants (Cantin et al. (2006b); Schwarzer et al. (2008); Raju et al. (2013); Lambert et al. (2014); Schmid et al. (2015); Raju et al. (2016); Chinnapaiyan et al. (2018), which could be reversed upon antioxidant treatment Raju et al. (2013); Lambert et al. (2014); Schmid et al. (2015). Similar observations were made under hypoxic conditions Brézillon et al. (1997); Zhang et al. (2013); Woodworth, (2015). Antioxidants could also increase $\mathrm{Cl}^{-}$conductance and anion transport in the absence of oxidant treatment or hypoxia induction in human and murine respiratory cells in vitro and in ex vivo tissues Azbell et al. (2010); Alexander et al. (2011); Conger et al. (2013). Healthy smokers and smokers with COPD have reduced $\mathrm{Cl}^{-}$ conductance Sloane et al. (2012); Dransfield et al. (2013) and increased sweat chloride concentrations Raju et al. (2013); Courville et al. (2014)

KERB

Decreased CFTR function leading to decreased ASL height

Strong As a major $\mathrm{Cl}^{-}$channel in the respiratory epithelium, CFTR levels and function are vital for maintenance of ASL homeostasis. In vitro studies on the effects of cigarette smoke exposure on human lung primary cells and cell lines showed a reduction in ASL height, associated with decreased CFTR levels Hassan et al. (2014); Rasmussen et al. (2014); Xu et al. (2015); Ghosh et al. (2017) and decreased Cl${ }^{-}$current Lambert et al. (2014); Raju et al. (2016). Moreover, pharmaceutical stimulation and inhibition of CFTR function and expression directly increased and decreased ASL height, respectively Song et al. (2009); Van Goor et al. (2009); Van Goor et al. (2011); Tuggle et al. (2014)

KERC

Decreased ASL height leading to decreased CBF
Weak Concurrent ASL height and CBF decreases were noted in human 3D airway epithelial cultures following exposure to cigarette smoke Åstrand et al. (2014); Xu et al. (2015) and following the addition of large dextran molecules, low-melting point agarose or endogenous mucus Button et al. (2012). Treatment of human airway epithelial with an ENaC inhibitor prevented the cigarette smoke effect on ASL height and CBF Åstrand et al. (2014). In addition, treatment of cystic fibrosis airway cultures with a CFTR-modifying drug increased both ASL height and CBF Van Goor et al. (2009)

A decrease in CBF resulting from sulfur dioxide exposure reduced mucociliary clearance in dogs Yeates et al. (1997) and mucociliary activity in guinea pig tracheas Knorst et al. (1994). In rats, formaldehyde inhalation exposure resulted in lower numbers of ciliated cells, while ciliary activity and mucus flow rates were decreased in a dose and time-dependent manner (Morgan et al. (1986). In humans, CBF positively correlates with nasal mucociliary clearance time Ho et al. (2001), and bronchiectasis patients have lower nasal CBF and slower mucociliary transport (MCT) Rutland and Cole, (1981). Administration of nebulized CBF inhibitors and enhancers quantifiably decreased or increased mucociliary clearance, respectively Boek et al. (1999); Boek et al. (2002). Increased CBF and MCT was also noted in human sinonasal epithelial cell cultures treated with Myrtol $^{\circledR}$, an essential oil distillate Lai et al. (2014) and in sheep tracheas and human airway epithelial cultures subjected to temperature changes Kilgour et al. (2004); Sears et al. (2015). Exposures of frog palate epithelia to formaldehyde and PM10 reduced MCC and mucociliary transport, but only formaldehyde-treated epithelia showed decreases in CBF Morgan et al. (1984); Macchione et al. (1999); Fló-Neyret et al. (2001)

Decreased CBF leading to decreased MCC Ex vivo treatment of sheep trachea with acetylcholine and epinephrine increased CBF, but only acetylcholine increased surface liquid velocity, while both parameters were decreased upon incubation with platelet-activating factor Seybold et al. (1990)

KERE

Decreased MCC leading to decreased lung function

Moderate Changes in MCC rate are typically paralleled by effects on lung function in several studies where both endpoints have been assessed. In patients with primary ciliary dyskinesia, absence of cilia motion prevents normal MCC and consequently, lung function is reduced Denizoglu Kulli et al. (2020). In cystic fibrosis patients, the ASL is depleted resulting in impaired MCC Boucher, (2004). Although the known CFTR genotypes can result in a variety of phenotypes Derichs, (2013), clinical data indicate that some specific gene defects, such as the p.Phe508del variant, are more frequently associated with decreased lung function indices (e.g. FEV1\% predicted, FVC \% predicted, FEF25-75) Kerem et al. (1990); Johansen et al. (1991); Schaedel et al. (2002). Both cigarette smoking and occupational exposure to biomass fumes led to slower MCC and reduced FEV1\% predicted and FEV1/FVC Ferreira et al. (2018). Nasomucociliary clearance was slower in COPD smokers compared to former smokers with COPD or to nonsmokers Ito et al. (2015). Allergen challenge in asthma patients resulted in both reduced MCC and FEV1, which could be reversed by inhalation of hypertonic saline solution Alexis et al. (2017). In cystic fibrosis patients, treatment with mucolytic agents Laube et al. (1996); McCoy et al. (1996); Quan et al. (2001); Elkins et al. (2006); Amin et al. (2011); Donaldson et al. (2018) or a CFTR potentiator Rowe et al. (2014) improved both MCC and lung function (FEV1, FVC and FEF25-75)

KERF

Oxidative stress leading to decreased FOXJ1 protein
Moderate

Cigarette smoke-induced oxidative stress downregulates FOXJ1 expression at both the gene and protein levels in human lung cells in vitro Milara et al. (2012); Brekman et al. (2014); Valencia-Gattas et al. (2016); Ishikawa and Ito, (2017). Oxidative stress induced by human respiratory syncytial virus reduces FOXJ1 mRNA levels, which can be restored by treatment with antioxidants or the phosphodiesterase 4 inhibitor roflumilast N-oxide Akaike et al. (1990); Geiler et al. (2010); Mata et al. (2012). In mice, thoracic irradiation results in free radical generation and subsequent reduction in FOXJ1 mRNA expression (Continued on following page) 
TABLE 1 | (Continued) Empirical evidence for key event relationships (KER).

KERG

Strong

Decreased FOXJ1 protein leading to decreased motile cilia length/number
Bernard et al. (2012). Many genes that are transcriptionally regulated by FOXJ1 are also downregulated following exposure to cigarette smoke, which implies a reduction in FOXJ1 transcriptional activity Brekman et al. (2014)

Homozygous null mutation of Foxj1 results in complete absence of cilia in mouse respiratory epithelium Chen et al. (1998); Brody et al. (2000). In a previous study, wild-type mice had approximately $20 \%$ heavily ciliated cells in the proximal pulmonary epithelium, while explanted Foxj $1^{-/-}$mouse trachea had no ciliated cells Gomperts et al. (2004). Loss of FOXJ1 orthologs FoxJ1-4 in flatworm Schmidtea mediterranea results in loss of ciliation of the ventral epithelium which closely resembles the human airway epithelium Rompolas et al. (2009); Vij et al. (2012). Loss of Foxj1 activity in Xenopus and zebrafish-through antisense morpholino oligonucleotides-reduces cilia formation, while, conversely, ectopic Foxj1 overexpression results in formation of multiple motile cilia Stubbs et al. (2008); Yu et al. (2008). There is a strong correlation between FOXJ1 and expression of the FOXJ1 ciliogenesis program genes in zebrafish, Xenopus and mouse cells Abedalthagafi et al. (2016)

Treatment with cigarette smoke extract downregulates FOXJ1 mRNA and protein expression, which is accompanied by a reduction in cilia length and number in human bronchial epithelial cells in vitro Milara et al. (2012); Brekman et al. (2014). This can be prevented by overexpression of FOXJ1 Brekman et al. (2014) or treatment with roflumilast N-oxide, which reduces intracellular free radical levels and increases FOXJ1 mRNA and protein expression Milara et al. (2012)
KERH

Moderate

Decreased motile cilia length/number leading to decreased CBF

KERI

Decreased ASL height leading to increased mucus viscosity

Moderate The phenomenon of ASL volume changes determining mucus viscosity is well described in the cystic fibrosis literature. In patients with this genetic defect, impaired CFTR function results in ASL depletion and mucus hyperviscosity Knowles and Boucher, (2002); Puchelle et al. (2002); Mall et al. (2004); Tarran, (2004). This has been confirmed experimentally in pig and rat models of this disease Birket et al. (2014); Birket et al. (2016); Birket et al. (2018). Studies with transgenic mice overexpressing $\beta \mathrm{ENaC}$ in the airways also corroborate the link between ASL dehydration and increased mucus viscosity, evidenced by the increased incidence of airway mucus plugging $[129,195]$. In a ferret model of cigarette smoke-induced COPD, ASL depletion was shown to be one of the drivers of increased mucus viscosity and decreased MCC Lin et al. (2020). The same study also showed that mucus from COPD patients, obtained from 3D organotypic airway epithelial cultures from different smoking donors with COPD, is significantly more viscous than that from healthy, non-smoking individuals and smokers without disease Lin et al. (2020)

Strong Experimental studies in vitro have shown that exposure of ciliated respiratory cells directly or indirectly to sources of oxidative stress leads to decreased CBF Burman and Martin, (1986); Wilson et al. (1987); Feldman et al. (1994); Yoshitsugu et al. (1995); Min et al. (1999), which can be reversed by treatment with antioxidants Schmid et al. (2015). Cigarette smoke condensate, a known inducer of oxidative stress, also causes a decrease in CBF in vitro Cohen et al. (2009), while, in human subjects exposed to different oxygen levels, oxygen stress causes a decrease in nasal CBF Stanek et al. (1998) Moderate Several studies have shown that there is an optimal range of viscoelastic mucus properties that facilitates efficient MCC and that changes in mucus viscosity beyond that optimal range impact CBF and alter MCC. Studies in humans, mice, hamsters, horses and frogs have shown that increased mucus viscosity correlates with a decrease in CBF King, (1979); Gheber et al. (1998); Matsui et al. (1998); Andrade et al. (2005); González et al. (2016); Kikuchi et al. (2017); Birket et al. (2018)

KERL

Increased mucus viscosity leading to decreased MCC

Moderate Mucus viscoelastic properties, whether altered by airway dehydration or mucus hypersecretion, directly influence MCC. Studies cystic fibrosis models and those on mimicking changes in mucus viscosity by using (bio)polymers or large molecules such as dextran have indicated a dose-response effect of increasing mucus viscosity on mucociliary transport rates, although these changes are transient in nature in ex vivo and in vitro systems Birket et al. (2018); Fernandez-Petty et al. (2019). Increased mucus viscosity also has a negative impact on MCC in horses with recurrent airway obstruction Gerber et al. (2000). Conversely, inhalation of hypertonic saline solution decreases mucus viscosity and enhances MCC in cystic fibrosis patients Robinson et al. (1997)

Abbreviations: $3 D$, three-dimensional; $A S L$, airway surface liquid; $C B F$, ciliary beating frequency; CFTR, cystic fibrosis transmembrane regulator; $C^{-}$, chloride (ion); COPD, chronic obstructive pulmonary disease; ENaC, epithelial sodium channel; FEF25-75, forced expiratory flow between 25 and 75\% of FVC; FEV1, forced expiratory volume in 1 s; FOR20, centromere protein 20; FOXJ1, forkhead box J1; FVC, forced vital capacity; MCC, mucociliary clearance; MCT, mucociliary transport.

Serous and glandular secretions of the airway epithelium contribute to the ASL, and epithelial ion channel function is critical to ASL homeostasis. Absorption of liquid to and from the mucus layer serves to maintain ASL depth. The regulation of these reabsorption processes is complex and not fully elucidated (Boucher, 2004). Experimental evidence suggests that the balance between $\mathrm{Na}^{+}$absorption and $\mathrm{Cl}^{-}$secretion-mediated by $\mathrm{ENaC}$ and CFTR, respectively-plays a major role in these processed, with the ion channels affecting each other's activity (Boucher, 2003; Boucher, 2004; Schmid et al., 2011). Impaired functioning of the CFTR and $\mathrm{ENaC}$ ion channels results in enhanced $\mathrm{Na}^{+}$absorption, reduced $\mathrm{Cl}^{-}$secretion, and consequently, reduced ASL height (KE2). This phenomenon is well known not only from studies in models of cystic fibrosis and acquired CFTR deficiency-even though the exact mechanism of the interaction between these two channels remains to be elucidated (Tarran et al., 2001; Boucher, 2003; Zhang et al., 2013; Hassan et al., 2014; Rasmussen et al., 2014; Woodworth, 2015; Raju et al., 2016) —but also from studies with pharmacological agents that enhance CFTR expression and/or 
function or perturb the interaction between CFTR and ENaC (Van Goor et al., 2009; Van Goor et al., 2011; Lambert et al., 2014).

Under physiological conditions, ASL height is adjusted to the appropriate height, which helps maintain the PCL depth at approximately the length of the cilia (Antunes and Cohen, 2007). If the airways become "dehydrated" (i.e., the ASL height decreases; KE2), the cilia collapse and ciliary movement is slowed or inhibited (KE6) (Matsui et al., 1998; Tarran et al., 2001; Knowles and Boucher, 2002; Munkholm and Mortensen, 2014). Decreased ASL height also contributes to increased mucus viscosity (KE5), a phenomenon that is well described in cystic fibrosis, where CFTR defect results in decreased ASL height, leading to decreased MCC (KE7) and subsequent mucus plugging (Birket et al., 2014; Birket et al., 2016; Birket et al., 2018).

Free radicals such as super oxides, hydroxyl radicals, and hydrogen peroxides are a common factor in various respiratory diseases, such as acute respiratory distress syndrome, asthma and pneumonia. Oxidative stress (such as that caused by cigarette smoke exposure or irradiation) leads to decreased FOXJ1 gene and protein expression (KE3) as well as to decreased FOXJ1 target gene expression (Milara et al., 2012; Brekman et al., 2014; GarciaArcos et al., 2016; Valencia-Gattas et al., 2016; Ishikawa and Ito, 2017). Because FOXJ1 is a key factor of multiple motile cilia assembly in the respiratory airways (Zhou and Roy, 2015), oxidative stress blocks the multiciliogenesis program, which is necessary and also sufficient to program cells to grow functional motile cilia (Hua et al., 2010; Vij et al., 2012). Studies in different model organisms have shown that the loss of FOXJ1 (KE3) results in a loss of multiple motile cilia (KE4) (Chen et al., 1998; Brody et al., 2000; Stubbs et al., 2008; Vij et al., 2012).

Cilia in the respiratory epithelium beat in a coordinated fashion at a frequency of approximately $7-16 \mathrm{~Hz}$, propelling mucus upwards (Joki et al., 1998; Smith et al., 2012; Jing et al., 2017). Many factors have been shown to affect ciliary function, including cilia length, number, structure, orientation, and distribution as well as mucus viscosity, temperature, $\mathrm{pH}$, chemicals, ASL height, and exposure to bacterial and viral pathogens (Kanthakumar et al., 1996; Clary-Meinesz et al., 1998; Joki et al., 1998; Ho et al., 2001; Mall, 2008; Smith et al., 2012; Jing et al., 2017; Snyder et al., 2017). Alterations in normal physiological conditions and healthy cilia number/length/ structure (KE4) as well as oxidative stress through exposure to hydrogen peroxide or free radicals typically reduce CBF (KE6) (Burman and Martin, 1986; Clary-Meinesz et al., 1998; Min et al., 1999; Jayathilake et al., 2012).Synchronized ciliary action helps transport mucus from the lungs to the mouth, where it is swallowed or expectorated (Munkholm and Mortensen, 2014). In addition to ASL and mucus properties, the speed of mucus movement-and hence the effectiveness of MCC-is dependent on ciliary amplitude and beat frequency (Rubin, 2002). Aside from genetic defects leading to ciliopathies, there is ample evidence that prolonged exposure to noxious agents, such as cigarette smoke, nitrogen oxide and sulfur dioxide, causes a decrease in CBF (KE6) and, subsequently, MCC (KE7) (Knorst et al., 1994; Yeates et al., 1997; Kakinoki et al., 1998; Cohen et al., 2009; Schmid et al., 2015). CBF also seems to be dependent on mucus viscosity, with the $\mathrm{CBF}$ decreasing with increasing viscosity in animal models (Andrade et al., 2005; Kikuchi et al., 2017). This linear correlation between CBF (KE7) and mucus viscosity (KE5) has also been confirmed in mathematical models simulating the two-layer mucociliary transport process (Lee et al., 2011; Sedaghat et al., 2016).

Finally, the link between decreased MCC and decreased lung function $(\mathrm{AO})$ is well established through observations in patients with ciliary defects (e.g., primary ciliary dyskinesia) and cystic fibrosis. Failure to clear mucus from the lungs causes mucus build up, which can lead to mucus plugging in the airways and, consequently, leads to decreased lung function over time (Mossberg et al., 1978; Regnis et al., 1994; Wanner et al., 1996; Robinson and Bye, 2002; Kerem et al., 2014; Szczesniak et al., 2017). Mucus plugging due to decreased MCC is also considered a major cause of airway obstruction and airflow limitation in COPD patients (Okajima et al., 2020; Dunican et al., 2021) and asthmatics (Maxwell, 1985; Kuyper et al., 2003).

\section{OVERALL ASSESSMENT OF THE ADVERSE OUTCOME PATHWAYS}

\subsection{Key Event Essentiality}

The definition of essentiality implies that modulation of upstream KEs impacts the downstream KEs in an expected fashion. When blocked or when they fail to occur, the KEs in the current AOP will not necessarily stop the progression to subsequent KEs. Owing to the complex biology of motile cilia formation and function, ASL homeostasis, mucus properties, and MCC, the KEs and AO may be triggered because of alternative pathways or biological redundancies. However, when exacerbated, the KEs promote the occurrence of downstream events that eventually lead to the AO. The causal pathway starting from exposure to oxidants and leading to decreased lung function involves parallel routes with KEs, each of which is sufficient to cause the downstream KE to occur. Different mechanisms-such as oxidant-induced decreases in ASL height due to CFTR function decline or oxidant-induced decrease in cilia number and length as a result of decreased FOXJ1 levels-lead to decreased CBF and decreased MCC. Each of these pathways contributes to the AO, but their relative contributions are difficult to evaluate. We judge the KEs MIE, KE1, KE3, KE4, KE6, and KE7 as highly essential and suggest moderate essentiality for KE2 and KE5 (Table 1; AOPwiki, https://aopwiki.org/aops/411, https:// aopwiki.org/aops/424, https://aopwiki.org/aops/425).

\subsection{Key Event Relationship Biological Plausibility}

Mechanistic data on the pathways that contribute to oxidative stress-elicited lung damage have varied coverage in current literature. The AOP network we present here starts with an oxidant exposure or exposure-causing oxidative stress leading to decreased CFTR and FOXJ1 mRNA and protein levels as well as decreased protein function. KERA (oxidative stress leading to 
decreased CFTR function) is supported by multiple studies across different species, which suggest their high biological plausibility (for empirical evidence supporting each KER, refer to Table 1). For a similar inhibitory role of oxidative stress on FOXJ1, the studies are less ample. However, there is credible evidence that oxidative stress has a deteriorating effect on FOXJ1 transcript and protein levels as well as on the function of this transcription factor. Therefore, we judge the plausibility of KERF (oxidative stress leading to decreased FOXJ1 protein) to be moderate.

The biological functions of CFTR and FOXJ1 are extensively studied and established across different test systems, implying the high biological plausibility of both KERB (decreased CFTR function leading to decreased ASL height) and KERG (decreased FOXJ1 protein leading to decreased motile cilia length/number). Specifically, CFTR contributes to healthy lung function by regulating epithelial ion conductance to support ASL height maintenance (Boucher, 2003; Csanady et al., 2019), and FOXJ1 is an essential factor for functional multiple motile cilia assembly (Vij et al., 2012; Choksi et al., 2014). Both decreased ASL height (KE2) and decreased motile cilia length/number (KE4) lead to decreased CBF (KE6), as outlined in KERC and KERH, respectively. Multiple studies describe the link between decreased ASL height and reduced CBF. However, the causality between these KEs is not wellestablished, prompting us to judge KERC as weakly supported. As for KERH, higher numbers of motile cilia with a healthy length support efficient ciliary beating, and a decrease in cilia number and/or length results in a proportionate reduction in $\mathrm{CBF}$. This causal relationship is logical but is directly tested only in few studies. Therefore, we rank the biological plausibility of KERH as moderate. ASL height is also linked to the physical properties of mucus, and studies in models of or individuals with cystic fibrosis support the link between ASL depletion and increased mucus viscosity (KERI), though the overall evidence is sparse, and causality is not always proven. Because the dependencies between these two KEs were highlighted in different species in vitro and in vivo, and the underlying mechanism is well established, we judge the plausibility of KERI as moderate.

Additionally, we propose a direct relationship between oxidative stress and KE6, decreased CBF (KERJ). A variety of oxidants, such as hydrogen peroxide, nitric dioxide, sulfur dioxide, acetaldehyde, ozone, and cigarette smoke decrease $\mathrm{CBF}$ in airway epithelial cells in a dose- and time-dependent manner after exposure. This link is demonstrated in several studies in various species, and we judge the plausibility of KERJ as strong. Synchronized ciliary beating helps transport mucus from the distal airways to the mouth, where it is cleared through ingestion or expectoration. In vivo studies and observations in patients with ciliopathies, respiratory infections, or allergies, and following exposure to inhaled toxicants that compromise ciliary function demonstrate that absent, decreased, or asynchronous cilia beating results in defective mucus clearance. Pharmacological studies have demonstrated that CBF stimulation typically results in MCC stimulation. While some results support both a dose-dependent response and temporal sequence of decreased CBF (KE6) leading to decreased MCC (KE7), most studies evaluate these KEs in parallel, and no clear causal linkage is affirmed. The same is true for increased mucus viscosity. Mucus viscoelastic properties, whether altered by airway dehydration or mucus hypersecretion, directly influence MCC. In fact, there is an inverse relationship between mucus viscosity and CBF (KERK) and mucus transport/ MCC (KERL), as demonstrated in several in vivo and ex vivo studies. A large proportion of these studies have employed (bio) polymers or other large organic molecules to mimic the mucus layer in the airways and the increase in its viscosity. In addition, some of these studies have shown that decreased mucus viscosity may also result in impairment of MCC. Therefore, a causal link is only tentatively supported. Because cilia function, ASL height, and mucus properties are intricately linked to each other as evidenced by cystic fibrosis studies, we consider the plausibility of KERD, KERK, and KERL as moderate.

Different routes lead to impaired MCC, such as smokingrelated oxidative stress, ciliary defects or CFTR mutations. Regardless of the route that leads to a reduction in MCC, individuals with impaired MCC exhibit decreased lung function. Moreover, many pharmacological treatments that enhance MCC also improve lung function. KE7 and the AO are thus closely related; however, as causal evidence is not always available, we judge the biological plausibility of KERE (decreased MCC leading to decreased lung function) as moderate.

The linear AOPs presented here have certain knowledge gaps; however, overall, we consider the biological plausibility of our AOP network as strong, as the network integrates different plausible pathways from the same MIE, leading to a common AO. For example, while oxidative stress leading to decreased lung function through the branch $\mathrm{MIE} \rightarrow \mathrm{KE} 1 \rightarrow \mathrm{KE} 2 \rightarrow \mathrm{KE} 5$ and/or KE6 $\rightarrow$ KE7 $\rightarrow$ AO has a weakly supported link represented by KERC (KE2 $\rightarrow$ KE6, i.e., decreased ASL height leading to decreased CBF), the oxidative stress can lead to the $\mathrm{AO}$ also through $\mathrm{MIE} \rightarrow \mathrm{KE} 6 \rightarrow$ $\mathrm{KE} 7 \rightarrow \mathrm{AO}$ or via decreased FOXJ1 protein levels through $\mathrm{MIE} \rightarrow$ $\mathrm{KE} 3 \rightarrow \mathrm{KE} 4 \rightarrow \mathrm{KE} 5$ and/or KE6 $\rightarrow \mathrm{KE} 7 \rightarrow \mathrm{AO}$.

\section{DISCUSSION AND CONCLUSION}

Here, we have presented an AOP that links oxidative stress resulting from inhalation exposure to toxicants to impaired lung function via a decrease in MCC. Given the individual and public health burden of the consequences of lung function impairment, gaining a greater understanding of the underlying mechanisms of this pathology is extremely important in the risk assessment of inhaled toxic chemicals. There is strong empirical evidence to support several of the KERs in this AOP, particularly at the cellular level (i.e., oxidative stress leading to decreased CFTR function [KERA], decreased CFTR function leading to decreased ASL height [KERB], and oxidative stress leading to decreased CBF [KERJ]). However, additional evidence on causality is required to attribute stronger plausibility to KERs such as that between decreased ASL height and decreased CBF (KERC), which we evaluated as being weak. Future studies, using in vitro assays such as those outlined in Supplementary Table S1, that directly assess this linkage as well as the KERs we determined to have moderate plausibility (i.e., KERD, 
KERE, KERF, KERH, KERI, KERK, and KERL) will help greatly strengthen this AOP overall.

An integrated assessment of substances with the potential to be inhaled, either intentionally or unintentionally, could incorporate inhalation exposure and dosimetry modelling to inform an in vitro assessment approach with appropriate exposure techniques and cell systems for assessing the KEs in this AOP (EPA's Office of Chemical Safety and Pollution Prevention, 2019). Standardization and robustness testing of assays against explicit performance criteria using suitable reference materials can greatly increase the level of confidence in their use for KE assessment (Petersen EJ. et al., 2021; Petersen E. J. et al., 2021). Much of the empirical evidence that supports the KERs in the qualitative AOP described here was obtained from in vitro studies using well-established methodologies for biological endpoint assessment (Supplementary Table S1). Being chemical-agnostic, this AOP can be applied to a variety of substances that share the AO. For example, impaired MCC and decreased lung function have a long-known relationship with smoking, but little is known about the consequences of the long-term use of alternative inhaled nicotine delivery products such as electronic cigarettes and heated tobacco products. This AOP can form the basis of an assessment strategy for evaluating the effects of exposure to aerosol from these products on the basis of the KEs identified here.

AOPs such as this one can play a central role in risk assessment strategies for a wide variety of regulatory purposes by providing mechanistic support to an integrated approach to testing and assessment (IATA; (Clippinger et al., 2018)) or defined approach (DA). IATAs are flexible frameworks that can be adapted to best address the regulatory question or purpose at hand. Unlike the assessment process within IATA that involves some level of expert judgement, DA uses rule-based fixed data interpretation procedure. Both DA and IATAs are a means to integrate existing data on a chemical (e.g., physicochemical properties and ADME [absorption, distribution, metabolism, and excretion] information) with an AOP-based in vitro testing strategy to generate data that does not currently exist (Willett, 2019). An important feature of these approaches is that they should also include a measure of uncertainty to facilitate regulatory decision-making. AOPs can be used in an iterative fashion to identify and reduce or resolve, where possible, areas of uncertainty by generating data to fill those knowledge gaps. Furthermore, a quantitative AOP could provide data that would be translated to prediction models for human risk assessment through the application of in vitro to in vivo extrapolation (IVIVE) approaches.

\section{DATA AVAILABILITY STATEMENT}

Publicly available datasets were analyzed in this study. This data can be found here: At the point of submission, evidence

\section{REFERENCES}

Abedalthagafi, M. S., Wu, M. P., Merrill, P. H., Du, Z., Woo, T., Sheu, S.-H., et al. (2016). Decreased FOXJ1 Expression and its Ciliogenesis Programme in has been gathered from the literature and compiled prior to populating the AOPwiki at https://aopwiki.org/aops/411, https://aopwiki.org/aops/424 and https://aopwiki.org/aops/ 425. Special care was taken to properly cite all original studies that were evaluated during AOP development and assessment.

\section{ETHICS STATEMENT}

Ethical approval was not provided for this study on human participants because the work presented here cites publicly available data (e.g. reports of clinical study results). No new/ additional studies in humans was conducted for the purpose of this work. Ethical review and approval was not required for the animal study because this work is based on the review of publicly available data (e.g. scientific articles), some of which came from animal experimentation. No new/ additional animal study was conducted for the purpose of the work presented here.

\section{AUTHOR CONTRIBUTIONS}

All authors listed have made significant contribution to the work (literature review and evaluation, development of AOP, synthesis of evidence, draft and revision of manuscript) and approved it for publication.

\section{FUNDING}

PMI is the sole source of funding and sponsor of this research.

\section{ACKNOWLEDGMENTS}

The authors thank Marja Talikka and Rex FitzGerald for their helpful discussions during AOP development. The authors are also grateful to Manuel C. Peitsch, Rex FitzGerald, Amy J. Clippinger, Andreas O. Stucki, and Holger Behrsing for critical review during the preparation of this article and to Sindhoora Bhargavi Gopala Reddy for editorial assistance.

\section{SUPPLEMENTARY MATERIAL}

The Supplementary Material for this article can be found online at: https://www.frontiersin.org/articles/10.3389/ftox.2021.750254/ full\#supplementary-material

Aggressive Ependymoma and Choroid Plexus Tumours. J. Pathol. 238 (4), 584-597. doi:10.1002/path.4682

Akaike, T., Ando, M., Oda, T., Doi, T., Ijiri, S., Araki, S., et al. (1990). Dependence on O2- Generation by Xanthine Oxidase of Pathogenesis of Influenza Virus Infection in Mice. J. Clin. Invest. 85 (3), 739-745. doi:10.1172/JCI114499 
Alexander, N. S., Hatch, N., Zhang, S., Skinner, D., Fortenberry, J., Sorscher, E. J., et al. (2011). Resveratrol Has Salutary Effects on Mucociliary Transport and Inflammation in Sinonasal Epithelium. Laryngoscope 121 (6), 1313-1319. doi:10.1002/lary.21798

Alexander, N. S., Blount, A., Zhang, S., Skinner, D., Hicks, S. B., Chestnut, M., et al. (2012). Cystic Fibrosis Transmembrane Conductance Regulator Modulation by the Tobacco Smoke Toxin Acrolein. Laryngoscope 122 (6), 1193-1197. doi:10.1002/lary.23278

Alexis, N. E., Bennett, W., and Peden, D. B. (2017). Safety and Benefits of Inhaled Hypertonic saline Following Airway Challenges with Endotoxin and Allergen in Asthmatics. J. Asthma 54 (9), 957-960. doi:10.1080/ 02770903.2016.1278019

Althaus, M. (2013). ENaC Inhibitors and Airway Re-Hydration in Cystic Fibrosis: State of the Art. Curr. Mol. Pharmacol. 6 (1), 3-12. doi:10.2174/ 18744672112059990025

Amin, R., Subbarao, P., Lou, W., Jabar, A., Balkovec, S., Jensen, R., et al. (2011). The Effect of Dornase Alfa on Ventilation Inhomogeneity in Patients with Cystic Fibrosis. Eur. Respir. J. 37 (4), 806-812. doi:10.1183/09031936.00072510

Andrade, Y. N., Fernandes, J., Va'zquez, E., Ferna'ndez-Ferna'ndez, J. M., Arniges, M., Sa'nchez, T. M., et al. (2005). TRPV4 Channel Is Involved in the Coupling of Fluid Viscosity Changes to Epithelial Ciliary Activity. J. Cel Biol. 168 (6), 869-874. doi:10.1083/jcb.200409070

Ankley, G. T., Bennett, R. S., Erickson, R. J., Hoff, D. J., Hornung, M. W., Johnson, R. D., et al. (2010). Adverse Outcome Pathways: a Conceptual Framework to Support Ecotoxicology Research and Risk Assessment. Environ. Toxicol. Chem. 29 (3), 730-741. doi:10.1002/etc.34

Antunes, M. B., and Cohen, N. A. (2007). Mucociliary Clearance - a Critical Upper Airway Host Defense Mechanism and Methods of Assessment. Curr. Opin. Allergy Clin. Immunol. 7 (1), 5-10. doi:10.1097/aci.0b013e3280114eef

Arbi, M., Pefani, D. E., Kyrousi, C., Lalioti, M. E., Kalogeropoulou, A., Papanastasiou, A. D., et al. (2016). GemC1 Controls Multiciliogenesis in the Airway Epithelium. EMBO Rep. 17 (3), 400-413. doi:10.15252/ embr.201540882

Åstrand, A. B., Hemmerling, M., Root, J., Wingren, C., Pesic, J., Johansson, E., et al. (2014). Linking Increased Airway Hydration, Ciliary Beating, and Mucociliary Clearance through ENaC Inhibition. Am. J. Physiol. Lung Cel. Mol. Physiol. 308 (1), L22-L32. doi:10.1152/ajplung.00163.2014

Azbell, C., Zhang, S., Skinner, D., Fortenberry, J., Sorscher, E. J., and Woodworth, B. A. (2010). Hesperidin Stimulates Cystic Fibrosis Transmembrane Conductance Regulator-Mediated Chloride Secretion and Ciliary Beat Frequency in Sinonasal Epithelium. Otolaryngol. Head Neck Surg. 143 (3), 397-404. doi:10.1016/j.otohns.2010.05.021

Bargon, J., Trapnell, B. C., Yoshimura, K., Dalemans, W., Pavirani, A., Lecocq, J. P., et al. (1992a). Expression of the Cystic Fibrosis Transmembrane Conductance Regulator Gene Can Be Regulated by Protein Kinase C. J. Biol. Chem. 267 (23), 16056-16060. doi:10.1016/s0021-9258(18)41964-3

Bargon, J., Trapnell, B. C., Chu, C. S., Rosenthal, E. R., Yoshimura, K., Guggino, W. B., et al. (1992b). Down-regulation of Cystic Fibrosis Transmembrane Conductance Regulator Gene Expression by Agents that Modulate Intracellular Divalent Cations. Mol. Cel. Biol. 12 (4), 1872-1878. doi:10.1128/mcb.12.4.1872-1878.1992

Berlett, B. S., and Stadtman, E. R. (1997). Protein Oxidation in Aging, Disease, and Oxidative Stress. J. Biol. Chem. 272 (33), 20313-20316. doi:10.1074/ jbc.272.33.20313

Bernard, M. E., Kim, H., Rajagopalan, M. S., Stone, B., Salimi, U., Rwigema, J. C., et al. (2012). Repopulation of the Irradiation Damaged Lung with Bone Marrow-Derived Cells. In Vivo 26 (1), 9-18.

Berta, T., Gabriele, P., Sandra, S.-B., Gabriel, G.-G., Youssef, S. A., StephanOtto, A. C., et al. (2016). GEMC1 Is a Critical Regulator of Multiciliated Cell Differentiation. EMBO J. 35 (9), 942-960. doi:10.15252/ embj.201592821

Birket, S. E., Chu, K. K., Liu, L., Houser, G. H., Diephuis, B. J., Wilsterman, E. J., et al. (2014). A Functional Anatomic Defect of the Cystic Fibrosis Airway. Am. J. Respir. Crit. Care Med. 190 (4), 421-432. doi:10.1164/ rccm.201404-0670oc

Birket, S. E., Chu, K. K., Houser, G. H., Liu, L., Fernandez, C. M., Solomon, G. M., et al. (2016). Combination Therapy with Cystic Fibrosis Transmembrane Conductance Regulator Modulators Augment the Airway Functional
Microanatomy. Am. J. Physiol. Lung Cell Mol. Physiol. 310 (10), L928-L939. doi:10.1152/ajplung.00395.2015

Birket, S. E., Davis, J. M., Fernandez, C. M., Tuggle, K. L., Oden, A. M., Chu, K. K., et al. (2018). Development of an Airway Mucus Defect in the Cystic Fibrosis Rat. JCI Insight 3 (1), e97199. doi:10.1172/jci.insight.97199

Bodas, M., Silverberg, D., Walworth, K., Brucia, K., and Vij, N. (2017). Augmentation of S-Nitrosoglutathione Controls Cigarette Smoke-Induced Inflammatory-Oxidative Stress and Chronic Obstructive Pulmonary DiseaseEmphysema Pathogenesis by Restoring Cystic Fibrosis Transmembrane Conductance Regulator Function. Antioxid. Redox Signal. 27 (7), 433-451. doi:10.1089/ars.2016.6895

Boek, W. M., Keleş, N., Graamans, K., and Huizing, E. H. (1999). Physiologic and Hypertonic saline Solutions Impair Ciliary Activity In Vitro. Laryngoscope 109 (3), 396-399. doi:10.1097/00005537-199903000-00010

Boek, W. M., Graamans, K., Natzijl, H., van Rijk, P. P., and Huizing, E. H. (2002). Nasal Mucociliary Transport: New Evidence for a Key Role of Ciliary Beat Frequency. Laryngoscope 112 (3), 570-573. doi:10.1097/00005537-20020300000029

Bottier, M., Thomas, K. A., Dutcher, S. K., and Bayly, P. V. (2019). How Does Cilium Length Affect Beating? Biophys. J. 116 (7), 1292-1304. doi:10.1016/ j.bpj.2019.02.012

Boucher, R. (2003). Regulation of Airway Surface Liquid Volume by Human Airway Epithelia. Pflugers Arch. - Eur. J. Physiol. 445 (4), 495-498. doi:10.1007/ s00424-002-0955-1

Boucher, R. C. (2004). New Concepts of the Pathogenesis of Cystic Fibrosis Lung Disease. Eur. Respir. J. 23 (1), 146-158. doi:10.1183/09031936.03.00057003

Braun, A. P. (2014). Cigarette Smoke and Calcium Conspire to Impair CFTR Function in Airway Epithelia. Channels 8 (3), 172-173. doi:10.4161/chan.28970 Brézillon, S., Zahm, J.-M., Pierrot, D., Gaillard, D., Hinnrasky, J., Millart, H., et al. (1997). ATP Depletion Induces a Loss of Respiratory Epithelium Functional Integrity and Down-Regulates CFTR (Cystic Fibrosis Transmembrane Conductance Regulator) Expression. J. Biol. Chem. 272 (44), 27830-27838. doi:10.1074/jbc.272.44.27830

Brekman, A., Walters, M. S., Tilley, A. E., and Crystal, R. G. (2014). FOXJ1 Prevents Cilia Growth Inhibition by Cigarette Smoke in Human Airway EpitheliumIn Vitro. Am. J. Respir. Cel Mol. Biol. 51 (5), 688-700. doi:10.1165/rcmb.20130363 oc

Brody, S. L., Yan, X. H., Wuerffel, M. K., Song, S.-K., and Shapiro, S. D. (2000). Ciliogenesis and Left-Right axis Defects in Forkhead Factor HFH-4-Null Mice. Am. J. Respir. Cel Mol. Biol. 23 (1), 45-51. doi:10.1165/ajrcmb.23.1.4070

Brooks, E. R., and Wallingford, J. B. (2014). Multiciliated Cells. Curr. Biol. 24 (19), R973-R982. doi:10.1016/j.cub.2014.08.047

Burman, W. J., and Martin, W. J. (1986). Oxidant-Mediated Ciliary Dysfunction. Chest 89 (3), 410-413. doi:10.1378/chest.89.3.410

Bustamante-Marin, X. M., and Ostrowski, L. E. (2017). Cilia and Mucociliary Clearance. Cold Spring Harb. Perspect. Biol. 9 (4), a028241. doi:10.1101/ cshperspect.a028241

Button, B., Cai, L.-H., Ehre, C., Kesimer, M., Hill, D. B., Sheehan, J. K., et al. (2012). A Periciliary brush Promotes the Lung Health by Separating the Mucus Layer from Airway Epithelia. Science 337 (6097), 937-941. doi:10.1126/ science. 1223012

Cantin, A. M., Bilodeau, G., Ouellet, C., Liao, J., and Hanrahan, J. W. (2006a). Oxidant Stress Suppresses CFTR Expression. Am. J. Physiology-Cell Physiol. 290 (1), C262-C270. doi:10.1152/ajpcell.00070.2005

Cantin, A. M., Hanrahan, J. W., Bilodeau, G., Ellis, L., Dupuis, A., Liao, J., et al. (2006b). Cystic Fibrosis Transmembrane Conductance Regulator Function Is Suppressed in Cigarette Smokers. Am. J. Respir. Crit. Care Med. 173 (10), 1139-1144. doi:10.1164/rccm.200508-1330OC

Chabot, F., Mitchell, J. A., Gutteridge, J. M., and Evans, T. W. (1998). Reactive Oxygen Species in Acute Lung Injury. Eur. Respir. J. 11 (3), 745-757.

Chen, J., Knowles, H. J., Hebert, J. L., and Hackett, B. P. (1998). Mutation of the Mouse Hepatocyte Nuclear Factor/forkhead Homologue 4 Gene Results in an Absence of Cilia and Random Left-Right Asymmetry. J. Clin. Invest. 102 (6), 1077-1082. doi:10.1172/JCI4786

Chilvers, M. A., and O'Callaghan, C. (2000). Analysis of Ciliary Beat Pattern and Beat Frequency Using Digital High Speed Imaging: Comparison with the Photomultiplier and Photodiode Methods. Thorax 55 (4), 314-317. doi:10.1136/thorax.55.4.314 
Chinnapaiyan, S., Dutta, R., Bala, J., Parira, T., Agudelo, M., Nair, M., et al. (2018). Cigarette Smoke Promotes HIV Infection of Primary Bronchial Epithelium and Additively Suppresses CFTR Function. Sci. Rep. 8, 7984. doi:10.1038/s41598018-26095-z

Choksi, S. P., Lauter, G., Swoboda, P., and Roy, S. (2014). Switching on Cilia: Transcriptional Networks Regulating Ciliogenesis. Development 141 (7), 1427-1441. doi:10.1242/dev.074666

Church, D. F., and Pryor, W. A. (1985). Free-radical Chemistry of Cigarette Smoke and its Toxicological Implications. Environ. Health Perspect. 64, 111-126. doi:10.1289/ehp.8564111

Clary-Meinesz, C., Mouroux, J., Cosson, J., Huitorel, P., and Blaive, B. (1998). Influence of External pH on Ciliary Beat Frequency in Human Bronchi and Bronchioles. Eur. Respir. J. 11 (2), 330-333. doi:10.1183/09031936.98.11020330

Clippinger, A. J., Allen, D., Behrsing, H., BéruBé, K. A., Bolger, M. B., Casey, W., et al. (2018). Pathway-based Predictive Approaches for Non-animal Assessment of Acute Inhalation Toxicity. Toxicol. Vitro 52, 131-145. doi:10.1016/j.tiv.2018.06.009

Clunes, L. A., Davies, C. M., Coakley, R. D., Aleksandrov, A. A., Henderson, A. G., Zeman, K. L., et al. (2012). Cigarette Smoke Exposure Induces CFTR Internalization and Insolubility, Leading to Airway Surface Liquid Dehydration. FASEB J. 26 (2), 533-545. doi:10.1096/fj.11-192377

Cohen, N. A., Zhang, S., Sharp, D. B., Tamashiro, E., Chen, B., Sorscher, E. J., et al. (2009). Cigarette Smoke Condensate Inhibits Transepithelial Chloride Transport and Ciliary Beat Frequency. Laryngoscope 119 (11), 2269-2274. doi:10.1002/lary.20223

Conger, B. T., Zhang, S., Skinner, D., Hicks, S. B., Sorscher, E. J., Rowe, S. M., et al. (2013). Comparison of Cystic Fibrosis Transmembrane Conductance Regulator (CFTR) and Ciliary Beat Frequency Activation by the CFTR Modulators Genistein, VRT-532, and UCCF-152 in Primary Sinonasal Epithelial Cultures. JAMA Otolaryngol. Head Neck Surg. 139 (8), 822-827. doi:10.1001/jamaoto.2013.3917

Courville, C. A., Tidwell, S., Liu, B., Accurso, F. J., Dransfield, M. T., and Rowe, S. M. (2014). Acquired Defects in CFTR-dependent $\beta$-Adrenergic Sweat Secretion in Chronic Obstructive Pulmonary Disease. Respir. Res. 15 (1), 25. doi:10.1186/1465-9921-15-25

Csanády, L., Vergani, P., and Gadsby, D. C. (2019). Structure, Gating, and Regulation of the Cftr Anion Channel. Physiol. Rev. 99 (1), 707-738. doi:10.1152/physrev.00007.2018

Denizoglu Kulli, H., Gurses, H. N., Zeren, M., Ucgun, H., and Cakir, E. (2020). Do pulmonary and Extrapulmonary Features Differ Among Cystic Fibrosis, Primary Ciliary Dyskinesia, and Healthy Children? Pediatr. Pulmonol. 55 (11), 3067-3073. doi:10.1002/ppul.25052

Derichs, N. (2013). Targeting a Genetic Defect: Cystic Fibrosis Transmembrane Conductance Regulator Modulators in Cystic Fibrosis. Eur. Respir. Rev. 22 (127), 58-65. doi:10.1183/09059180.00008412

Donaldson, S. H., Laube, B. L., Corcoran, T. E., Bhambhvani, P., Zeman, K., Ceppe, A., et al. (2018). Effect of Ivacaftor on Mucociliary Clearance and Clinical Outcomes in Cystic Fibrosis Patients with G551D-CFTR. JCI Insight 3 (24), e122695. doi:10.1172/jci.insight.122695

Dransfield, M. T., Wilhelm, A. M., Flanagan, B., Courville, C., Tidwell, S. L., Raju, S. V., et al. (2013). Acquired Cystic Fibrosis Transmembrane Conductance Regulator Dysfunction in the Lower Airways in COPD. Chest 144 (2), 498-506. doi:10.1378/chest.13-0274

Dunican, E. M., Elicker, B. M., Henry, T., Gierada, D. S., Schiebler, M. L., Anderson, W., et al. (2021). Mucus Plugs and Emphysema in the Pathophysiology of Airflow Obstruction and Hypoxemia in Smokers. Am. J. Respir. Crit. Care Med. 203 (8), 957-968. doi:10.1164/rccm.202006-2248oc

Elkins, M. R., Robinson, M., Rose, B. R., Harbour, C., Moriarty, C. P., Marks, G. B., et al. (2006). A Controlled Trial of Long-Term Inhaled Hypertonic Saline in Patients with Cystic Fibrosis. N. Engl. J. Med. 354 (3), 229-240. doi:10.1056/NEJMoa043900

EPA's Office of Chemical Safety and Pollution Prevention (2019). FIFRA Scientific Advisory Panel Meeting Minutes and Final Report No. 2019-01 Peer Review on Evaluation of a Proposed Approach to Refine the Inhalation Risk Assessment for Point of Contact Toxicity: A Case Study Using a New Approach Methodology (NAM) December 4 and 6, 2018 FIFRA Scientific Advisory Panel Meeting. Washington, DC: U.S. Environmental Protection Agency.

Fahy, J. V., and Dickey, B. F. (2010). Airway Mucus Function and Dysfunction. N. Engl. J. Med. 363 (23), 2233-2247. doi:10.1056/NEJMra0910061
Farinha, C. M., Matos, P., and Amaral, M. D. (2013). Control of Cystic Fibrosis Transmembrane Conductance Regulator Membrane Trafficking: Not Just from the Endoplasmic Reticulum to the Golgi. FEBS J. 280 (18), 4396-4406. doi: $10.1111 /$ febs. 12392

Feldman, C., Anderson, R., Kanthakumar, K., Vargas, A., Cole, P. J., and Wilson, R. (1994). Oxidant-mediated Ciliary Dysfunction in Human Respiratory Epithelium. Free Radic. Biol. Med. 17 (1), 1-10. doi:10.1016/0891-5849(94)90002-7

Fernandez-Petty, C. M., Hughes, G. W., Bowers, H. L., Watson, J. D., Rosen, B. H., Townsend, S. M., et al. (2019). A Glycopolymer Improves Vascoelasticity and Mucociliary Transport of Abnormal Cystic Fibrosis Mucus. JCI Insight 4 (8), e125954. doi:10.1172/jci.insight.125954

Ferreira, A. D., Ramos, E. M. C., Trevisan, I. B., Leite, M. R., Proença, M., de CarvalhoJunior, L. C. S., et al. (2018). Função pulmonar e depuração mucociliar nasal de cortadores de cana-de-açúcar brasileiros expostos à queima de biomassa. Rev. Bras. Saúde Ocup. 43, e6. doi:10.1590/2317-6369000004217

Fischer, H., and Widdicombe, J. H. (2006). Mechanisms of Acid and Base Secretion by the Airway Epithelium. J. Membr. Biol. 211 (3), 139-150. doi:10.1007/ s00232-006-0861-0

Fló-Neyret, C., Lorenzi-Filho, G., Macchione, M., Garcia, M. L., and Saldiva, P. H. (2001). Effects of Formaldehyde on the Frog's Mucociliary Epithelium as a Surrogate to Evaluate Air Pollution Effects on the Respiratory Epithelium. Braz. J. Med. Biol. Res. 34, 639-643. doi:10.1590/s0100-879x2001000500012

Fröhlich, E., Mercuri, A., Wu, S., and Salar-Behzadi, S. (2016). Measurements of Deposition, Lung Surface Area and Lung Fluid for Simulation of Inhaled Compounds. Front. Pharmacol. 7, 181. doi:10.3389/fphar.2016.00181

Garcia-Arcos, I., Geraghty, P., Baumlin, N., Campos, M., Dabo, A. J., Jundi, B., et al. (2016). Chronic Electronic Cigarette Exposure in Mice Induces Features of COPD in a Nicotine-dependent Manner. Thorax 71 (12), 1119-1129. doi:10.1136/thoraxjnl-2015-208039

Geiler, J., Michaelis, M., Naczk, P., Leutz, A., Langer, K., Doerr, H.-W., et al. (2010). $\mathrm{N}$-acetyl-L-cysteine (NAC) Inhibits Virus Replication and Expression of Proinflammatory Molecules in A549 Cells Infected with Highly Pathogenic H5N1 Influenza A Virus. Biochem. Pharmacol. 79 (3), 413-420. doi:10.1016/j.bcp.2009.08.025

Gerber, V., King, M., Schneider, D. A., and Robinson, N. E. (2000). Tracheobronchial Mucus Viscoelasticity during Environmental challenge in Horses with Recurrent Airway Obstruction. Equine Vet. J. 32 (5), 411-417. doi:10.2746/042516400777591183

Gerovac, B. J., and Fregien, N. L. (2016). IL-13 Inhibits Multicilin Expression and Ciliogenesis via Janus Kinase/signal Transducer and Activator of Transcription Independently of Notch Cleavage. Am. J. Respir. Cel Mol. Biol. 54 (4), 554-561. doi:10.1165/rcmb.2015-0227oc

Gerovac, B. J., Valencia, M., Baumlin, N., Salathe, M., Conner, G. E., and Fregien, N. L. (2014). Submersion and Hypoxia Inhibit Ciliated Cell Differentiation in a Notch-dependent Manner. Am. J. Respir. Cel Mol. Biol. 51 (4), 516-525. doi:10.1165/rcmb.2013-0237OC

Gheber, L., Korngreen, A., and Priel, Z. (1998). Effect of Viscosity on Metachrony in Mucus Propelling Cilia. Cell Motil. Cytoskeleton 39 (1), 9-20.

Ghosh, A., Abdelwahab, S. H., Reeber, S. L., Reidel, B., Marklew, A. J., Garrison, A. J., et al. (2017). Little Cigars Are More Toxic Than Cigarettes and Uniquely Change the Airway Gene and Protein Expression. Sci. Rep. 7, 46239. doi:10.1038/srep46239

Gomperts, B. N., Gong-Cooper, X., and Hackett, B. P. (2004). Foxj1 Regulates Basal Body Anchoring to the Cytoskeleton of Ciliated Pulmonary Epithelial Cells. J. Cel Sci. 117 (Pt 8), 1329-1337. doi:10.1242/jcs.00978

Gomperts, B. N., Kim, L. J., Flaherty, S. A., and Hackett, B. P. (2007). IL-13 Regulates Cilia Loss and Foxj1 Expression in Human Airway Epithelium. Am. J. Respir. Cel Mol. Biol. 37 (3), 339-346. doi:10.1165/rcmb.2006-0400OC

González, C., Droguett, K., Rios, M., Cohen, N. A., and Villalón, M. (2016). TNFa Affects Ciliary Beat Response to Increased Viscosity in Human Pediatric Airway Epithelium. Biomed. Res. Int. 2016, 3628501. doi:10.1155/2016/3628501

Halliwell, B., and Aruoma, O. I. (1991). DNA Damage by Oxygen-Derived Species. Its Mechanism and Measurement in Mammalian Systems. FEBS Lett. 281 (1-2), 9-19. doi:10.1016/0014-5793(91)80347-6

Hassan, F., Xu, X., Nuovo, G., Killilea, D. W., Tyrrell, J., Da Tan, C., et al. (2014). Accumulation of Metals in GOLD4 COPD Lungs Is Associated with Decreased CFTR Levels. Respir. Res. 15 (1), 69. doi:10.1186/1465-9921-15-69

Ho, J. C., Chan, K. N., Hu, W. H., Lam, W. K., Zheng, L., Tipoe, G. L., et al. (2001). The Effect of Aging on Nasal Mucociliary Clearance, Beat Frequency, and 
Ultrastructure of Respiratory Cilia. Am. J. Respir. Crit. Care Med. 163 (4), 983-988. doi:10.1164/ajrccm.163.4.9909121

Hobbs, C. A., Blanchard, M. G., Alijevic, O., Tan, C. D., Kellenberger, S., Bencharit, S., et al. (2013). Identification of the SPLUNC1 ENaC-Inhibitory Domain Yields Novel Strategies to Treat Sodium Hyperabsorption in Cystic Fibrosis Airway Epithelial Cultures. Am. J. Physiology-Lung Cell Mol. Physiol. 305 (12), L990-L1001. doi:10.1152/ajplung.00103.2013

Holland, J. A., Pritchard, K. A., Pappolla, M. A., Wolin, M. S., Rogers, N. J., and Stemerman, M. B. (1990). Bradykinin Induces Superoxide Anion Release from Human Endothelial Cells. J. Cel. Physiol. 143 (1), 21-25. doi:10.1002/jcp.1041430104

Hollenhorst, M. I., Richter, K., and Fronius, M. (2011). Ion Transport by Pulmonary Epithelia. Biomed. Res. Int. 2011, 174306. doi:10.1155/2011/174306

Hua, X., Zeman, K. L., Zhou, B., Hua, Q., Senior, B. A., Tilley, S. L., et al. (2010). Noninvasive Real-Time Measurement of Nasal Mucociliary Clearance in Mice by Pinhole Gamma Scintigraphy. J. Appl. Physiol. 108 (1), 189-196. doi:10.1152/japplphysiol.00669.2009

Ishikawa, S., and Ito, S. (2017). Repeated Whole Cigarette Smoke Exposure Alters Cell Differentiation and Augments Secretion of Inflammatory Mediators in Air-Liquid Interface Three-Dimensional Co-culture Model of Human Bronchial Tissue. Toxicol. Vitro 38, 170-178. doi:10.1016/j.tiv.2016.09.004

Ito, J. T., Ramos, D., Lima, F. F., Rodrigues, F. M., Gomes, P. R., Moreira, G. L., et al. (2015). Nasal Mucociliary Clearance in Subjects with COPD after Smoking Cessation. Respir. Care 60 (3), 399-405. doi:10.4187/respcare.03266

Jayathilake, P. G., Tan, Z., Le, D. V., Lee, H. P., and Khoo, B. C. (2012). Threedimensional Numerical Simulations of Human Pulmonary Cilia in the Periciliary Liquid Layer by the Immersed Boundary Method. Comput. Fluids 67, 130-137. doi:10.1016/j.compfluid.2012.07.016

Jayathilake, P. G., Le, D. V., Tan, Z., Lee, H. P., and Khoo, B. C. (2015). A Numerical Study of Muco-Ciliary Transport under the Condition of Diseased Cilia. Comput. Methods Biomech. Biomed. Eng. 18 (9), 944-951. doi:10.1080/ 10255842.2013.864285

Jing, J. C., Chen, J. J., Chou, L., Wong, B. J. F., and Chen, Z. (2017). Visualization and Detection of Ciliary Beating Pattern and Frequency in the Upper Airway Using Phase Resolved Doppler Optical Coherence Tomography. Sci. Rep. 7 (1), 8522. doi:10.1038/s41598-017-08968-x

Johansen, H. K., Nir, M., Koch, C., Schwartz, M., and Høiby, N. (1991). Severity of Cystic Fibrosis in Patients Homozygous and Heterozygous for $\Delta$ F508 Mutation. Lancet 337 (8742), 631-634. doi:10.1016/0140-6736(91)92449-c

Joki, S., Toskala, E., Saano, V., and Nuutinen, J. (1998). Correlation between Ciliary Beat Frequency and the Structure of Ciliated Epithelia in Pathologic Human Nasal Mucosa. Laryngoscope 108 (3), 426-430. doi:10.1097/00005537199803000-00021

Kakinoki, Y., Tanaka, A., Washio, Y., Yamada, K., Nakai, Y., Morimoto, K., et al. (1998). Nitrogen Dioxide Compromises Defence Functions of the Airway Epithelium. Acta Oto-Laryngol. 118 (538), 221-226. doi:10.1080/00016489850182972

Kanthakumar, K., Taylor, G. W., Cundell, D. R., Dowling, R. B., Johnson, M., Cole, P. J., et al. (1996). The Effect of Bacterial Toxins on Levels of Intracellular Adenosine Nucleotides and Human Ciliary Beat Frequency. Pulm. Pharmacol. 9 (4), 223-230. doi:10.1006/pulp.1996.0028

Kerem, E., Corey, M., Kerem, B.-s., Rommens, J., Markiewicz, D., Levison, H., et al. (1990). The Relation between Genotype and Phenotype in Cystic Fibrosis Analysis of the Most Common Mutation (AF508). N. Engl. J. Med. 323 (22), 1517-1522. doi:10.1056/nejm199011293232203

Kerem, E., Viviani, L., Zolin, A., MacNeill, S., Hatziagorou, E., Ellemunter, H., et al. (2014). Factors Associated with FEV1 Decline in Cystic Fibrosis: Analysis of the ECFS Patient Registry. Eur. Respir. J. 43 (1), 125-133. doi:10.1183/ 09031936.00166412

Kikuchi, K., Haga, T., Numayama-Tsuruta, K., Ueno, H., and Ishikawa, T. (2017). Effect of Fluid Viscosity on the Cilia-Generated Flow on a Mouse Tracheal Lumen. Ann. Biomed. Eng. 45 (4), 1048-1057. doi:10.1007/s10439-016-1743-y

Kilgour, E., Rankin, N., Ryan, S., and Pack, R. (2004). Mucociliary Function Deteriorates in the Clinical Range of Inspired Air Temperature and Humidity. Int. Care Med. 30 (7), 1491-1494. doi:10.1007/s00134-004-2235-3

King, M. (1979). Interrelation between Mechanical Properties of Mucus and Mucociliary Transport: Effect of Pharmacologic Interventions. Biorheology 16 (1-2), 57-68. doi:10.3233/bir-1979-161-210

King, M. (2006). Physiology of Mucus Clearance. Paediatric Respir. Rev. 7 (Suppl. 1), S212-S214. doi:10.1016/j.prrv.2006.04.199
Kinnula, V. L., Chang, L., Everitt, J. I., and Crapo, J. D. (1992). Oxidants and Antioxidants in Alveolar Epithelial Type II Cells: In Situ, Freshly Isolated, and Cultured Cells. Am. J. Physiol.-Lung Cell Mol. Physiol. 262 (1 Pt 1), L69-L77. doi:10.1152/ajplung.1992.262.1.L69

Kinnula, V. L., Crapo, J. D., and Raivio, K. O. (1995). Generation and Disposal of Reactive Oxygen Metabolites in the Lung. Lab. Invest. 73 (1), 3-19.

Knorst, M. M., Kienast, K., Riechelmann, H., Müller-Quernheim, J., and Ferlinz, R. (1994). Effect of Sulfur Dioxide on Mucociliary Activity and Ciliary Beat Frequency in guinea Pig Trachea. Int. Arch. Occup. Environ. Heath 65 (5), 325-328. doi:10.1007/BF00405697

Knowles, M. R., and Boucher, R. C. (2002). Mucus Clearance as a Primary Innate Defense Mechanism for Mammalian Airways. J. Clin. Invest. 109 (5), 571-577. doi:10.1172/jci0215217

Kulka, M., Dery, R., Nahirney, D., Duszyk, M., and Befus, A. D. (2005). Differential Regulation of Cystic Fibrosis Transmembrane Conductance Regulator by Interferon $\gamma$ in Mast Cells and Epithelial Cells. J. Pharmacol. Exp. Ther. 315 (2), 563-570. doi:10.1124/jpet.105.087528

Kuyper, L. M., Paré, P. D., Hogg, J. C., Lambert, R. K., Ionescu, D., Woods, R., et al. (2003). Characterization of Airway Plugging in Fatal Asthma. Am. J. Med. 115 (1), 6-11. doi:10.1016/s0002-9343(03)00241-9

Lai, S. K., Wang, Y.-Y., Wirtz, D., and Hanes, J. (2009). Micro- and Macrorheology of Mucus. Adv. Drug Deliv. Rev. 61 (2), 86-100. doi:10.1016/j.addr.2008.09.012

Lai, Y., Dilidaer, D., Chen, B., Xu, G., Shi, J., Lee, R. J., et al. (2014). In Vitro studies of a Distillate of Rectified Essential Oils on Sinonasal Components of Mucociliary Clearance. Am. J. Rhinol Allergy 28 (3), 244-248. doi:10.2500/ ajra.2014.28.4036

Lambert, J. A., Raju, S. V., Tang, L. P., McNicholas, C. M., Li, Y., Courville, C. A., et al. (2014). Cystic Fibrosis Transmembrane Conductance Regulator Activation by Roflumilast Contributes to Therapeutic Benefit in Chronic Bronchitis. Am. J. Respir. Cel Mol. Biol. 50 (3), 549-558. doi:10.1165/rcmb.2013-0228oc

Laube, B. L., Auci, R. M., Shields, D. E., Christiansen, D. H., Lucas, M. K., Fuchs, H. J., et al. (1996). Effect of rhDNase on Airflow Obstruction and Mucociliary Clearance in Cystic Fibrosis. Am. J. Respir. Crit. Care Med. 153 (2), 752-760. doi:10.1164/ajrccm.153.2.8564129

Lee, W. L., Jayathilake, P. G., Tan, Z., Le, D. V., Lee, H. P., and Khoo, B. C. (2011). Muco-ciliary Transport: Effect of Mucus Viscosity, Cilia Beat Frequency and Cilia Density. Comput. Fluids 49 (1), 214-221. doi:10.1016/ j.compfluid.2011.05.016

Lin, V. Y., Kaza, N., Birket, S. E., Kim, H., Edwards, L. J., LaFontaine, J., et al. (2020). Excess Mucus Viscosity and Airway Dehydration Impact COPD Airway Clearance. Eur. Respir. J. 55 (1), 1900419. doi:10.1183/ 13993003.00419-2019

Liu, M., Guan, Z., Shen, Q., Lalor, P., Fitzgerald, U., O’Brien, T., et al. (2016). Ulk4 Is Essential for Ciliogenesis and CSF Flow. J. Neurosci. 36 (29), 7589-7600. doi:10.1523/jneurosci.0621-16.2016

Macchione, M., Oliveira, A. P., Gallafrio, C. T., Muchão, F. P., Obara, M. T., Guimarães, E. T., et al. (1999). Acute Effects of Inhalable Particles on the Frog Palate Mucociliary Epithelium. Environ. Health Perspect. 107 (10), 829-833. doi:10.1289/ehp.99107829

Mall, M., Grubb, B. R., Harkema, J. R., O’Neal, W. K., and Boucher, R. C. (2004). Increased Airway Epithelial Na+ Absorption Produces Cystic Fibrosis-like Lung Disease in Mice. Nat. Med. 10 (5), 487-493. doi:10.1038/nm1028

Mall, M. A. (2008). Role of Cilia, Mucus, and Airway Surface Liquid in Mucociliary Dysfunction: Lessons from Mouse Models. J. Aerosol Med. Pulm. Drug Deliv. 21 (1), 13-24. doi:10.1089/jamp.2007.0659

Mata, M., Sarrion, I., Armengot, M., Carda, C., Martinez, I., Melero, J. A., et al. (2012). Respiratory Syncytial Virus Inhibits Ciliagenesis in Differentiated Normal Human Bronchial Epithelial Cells: Effectiveness of N-Acetylcysteine. PloS one 7 (10), e48037. doi:10.1371/journal.pone.0048037

Matsui, H., Grubb, B. R., Tarran, R., Randell, S. H., Gatzy, J. T., Davis, C. W., et al. (1998). Evidence for Periciliary Liquid Layer Depletion, Not Abnormal Ion Composition, in the Pathogenesis of Cystic Fibrosis Airways Disease. Cell 95 (7), 1005-1015. doi:10.1016/s0092-8674(00)81724-9

Maxwell, G. M. (1985). The Problem of Mucus Plugging in Children with Asthma. J. Asthma 22 (3), 131-137. doi:10.3109/02770908509073131

McCoy, K., Hamilton, S., and Johnson, C. (1996). Effects of 12-Week Administration of Dornase Alfa in Patients with Advanced Cystic Fibrosis Lung Disease. Chest 110 (4), 889-895. doi:10.1378/chest.110.4.889 
Milara, J., Armengot, M., Bañuls, P., Tenor, H., Beume, R., Artigues, E., et al. (2012). Roflumilast N-Oxide, a PDE4 Inhibitor, Improves Cilia Motility and Ciliated Human Bronchial Epithelial Cells Compromised by Cigarette Smoke In Vitro. Br. J. Pharmacol. 166 (8), 2243-2262. doi:10.1111/j.14765381.2012.01929.x

Min, Y.-G., Ohyama, M., Lee, K. S., Rhee, C.-S., Ha Oh, S., Sung, M.-W., et al. (1999). Effects of Free Radicals on Ciliary Movement in the Human Nasal Epithelial Cells. Auris Nasus Larynx 26 (2), 159-163. doi:10.1016/s03858146(98)00073-x

Morgan, K. T., Patterson, D. L., and Gross, E. A. (1984). Frog Palate Mucociliary Apparatus: Structure, Function, and Response to Formaldehyde Gas. Toxicol. Sci. 4 (1), 58-68. doi:10.1093/toxsci/4.1.58

Morgan, K. T., Patterson, D. L., and Gross, E. A. (1986). Responses of the Nasal Mucociliary Apparatus of F-344 Rats to Formaldehyde Gas. Toxicol. Appl. Pharmacol. 82 (1), 1-13. doi:10.1016/0041-008x(86)90431-x

Mossberg, B., Afzelius, B. A., Eliasson, R., and Camner, P. (1978). On the Pathogenesis of Obstructive Lung Disease. A Study on the Immotile-Cilia Syndrome. Scand. J. Respir. Dis. 59 (2), 55-65.

Munkholm, M., and Mortensen, J. (2014). Mucociliary Clearance: Pathophysiological Aspects. Clin. Physiol. Funct. Imaging 34 (3), 171-177. doi:10.1111/cpf.12085

National Research Council (1988). Air Pollution, the Automobile, and Public Health. Washington, DC: The National Academies Press.

OECD (2017). "Revised Guidance Document on Developing and Assessing Adverse Outcome Pathways," in Series on Testing and Assessment (Paris: Organisation for Economic Cooperation and Devleopment).

OECD (2018). "Users' Handbook Supplement to the Guidance Document for Developing and Assessing Adverse Outcome Pathways," in OECD Series on Adverse Outcome Pathways (Paris: OECD).

OECD (2021). Guideline No. 497: Defined Approaches on Skin Sensitisation. Paris, France: OECD Publishing.

Okajima, Y., Come, C. E., Nardelli, P., Sonavane, S. K., Yen, A., Nath, H. P., et al. (2020). Luminal Plugging on Chest CT Scan. Chest 158 (1), 121-130. doi:10.1016/j.chest.2019.12.046

Petersen, E. J., Nguyen, A., Brown, J., Elliott, J. T., Clippinger, A., Gordon, J., et al. (2021a). Characteristics to Consider when Selecting a Positive Control Material for an In Vitro Assay. Altex 38 (2), 365-376. doi:10.14573/altex.2102111

Petersen, E. J., Sharma, M., Clippinger, A. J., Gordon, J., Katz, A., Laux, P., et al. (2021b). Use of Cause-And-Effect Analysis to Optimize the Reliability of In Vitro Inhalation Toxicity Measurements Using an Air-Liquid Interface. Chem. Res. Toxicol. 34 (6), 1370-1385. doi:10.1021/acs.chemrestox.1c00080

Poli, G., and Parola, M. (1997). Oxidative Damage and Fibrogenesis. Free Radic. Biol. Med. 22 (1-2), 287-305. doi:10.1016/s0891-5849(96)00327-9

Puchelle, E., Bajolet, O., and Abély, M. (2002). Airway Mucus in Cystic Fibrosis. Paediatric Respir. Rev. 3 (2), 115-119. doi:10.1016/S1526-0550(02)00005-7

Qu, F., Qin, X.-Q., Cui, Y.-R., Xiang, Y., Tan, Y.-R., Liu, H.-J., et al. (2009). Ozone Stress Down-Regulates the Expression of Cystic Fibrosis Transmembrane Conductance Regulator in Human Bronchial Epithelial Cells. Chemico-Biol. Interact. 179 (2-3), 219-226. doi:10.1016/j.cbi.2008.10.059

Quan, J. M., Tiddens, H. A. W. M., Sy, J. P., McKenzie, S. G., Montgomery, M. D., Robinson, P. J., et al. (2001). A Two-Year Randomized, Placebo-Controlled Trial of Dornase Alfa in Young Patients with Cystic Fibrosis with Mild Lung Function Abnormalities. J. Pediatr. 139 (6), 813-820. doi:10.1067/ mpd.2001.118570

Rahman, I., and MacNee, W. (1996). Role of Oxidants/antioxidants in SmokingInduced Lung Diseases. Free Radic. Biol. Med. 21 (5), 669-681. doi:10.1016/ 0891-5849(96)00155-4

Rahman, I., Biswas, S. K., and Kode, A. (2006). Oxidant and Antioxidant Balance in the Airways and Airway Diseases. Eur. J. Pharmacol. 533 (1-3), 222-239. doi:10.1016/j.ejphar.2005.12.087

Raju, S. V., Jackson, P. L., Courville, C. A., McNicholas, C. M., Sloane, P. A., Sabbatini, G., et al. (2013). Cigarette Smoke Induces Systemic Defects in Cystic Fibrosis Transmembrane Conductance Regulator Function. Am. J. Respir. Crit. Care Med. 188 (11), 1321-1330. doi:10.1164/rccm.2013040733 oc

Raju, S. V., Lin, V. Y., Liu, L., Mcnicholas, C. M., Karki, S., Sloane, P. A., et al. (2016). The Cftr Potentiator Ivacaftor Augments Mucociliary Clearance
Abrogating Cftr Inhibition by Cigarette Smoke. Am. J. Respir. Cel Mol. Biol. 56 (1), 99-108. doi:10.1165/rcmb.2016-0226OC

Rasmussen, J. E., Sheridan, J. T., Polk, W., Davies, C. M., and Tarran, R. (2014). Cigarette Smoke-Induced Ca2+ Release Leads to Cystic Fibrosis Transmembrane Conductance Regulator (CFTR) Dysfunction. J. Biol. Chem. 289 (11), 7671-7681. doi:10.1074/jbc.M113.545137

Regnis, J. A., Robinson, M., Bailey, D. L., Cook, P., Hooper, P., Chan, H. K., et al. (1994). Mucociliary Clearance in Patients with Cystic Fibrosis and in normal Subjects. Am. J. Respir. Crit. Care Med. 150 (1), 66-71. doi:10.1164/ ajrccm.150.1.8025774

Rennolds, J., Butler, S., Maloney, K., Boyaka, P. N., Davis, I. C., Knoell, D. L., et al. (2010). Cadmium Regulates the Expression of the CFTR Chloride Channel in Human Airway Epithelial Cells. Toxicol. Sci. 116 (1), 349-358. doi:10.1093/ toxsci/kfq101

Riordan, J. R. (2008). CFTR Function and Prospects for Therapy. Annu. Rev. Biochem. 77 (1), 701-726. doi:10.1146/annurev.biochem.75.103004.142532

Robinson, M., and Bye, P. T. B. (2002). Mucociliary Clearance in Cystic Fibrosis. Pediatr. Pulmonol. 33 (4), 293-306. doi:10.1002/ppul.10079

Robinson, M., Hemming, A. L., Regnis, J. A., Wong, A. G., Bailey, D. L., Bautovich, G. J., et al. (1997). Effect of Increasing Doses of Hypertonic saline on Mucociliary Clearance in Patients with Cystic Fibrosis. Thorax 52 (10), 900-903. doi:10.1136/thx.52.10.900

Rompolas, P., Patel-King, R. S., and King, S. M. (2009). Schmidtea Mediterranea. Methods Cel. Biol. 93, 81-98. doi:10.1016/S0091-679X(08)93004-1

Rowe, S. M., Heltshe, S. L., Gonska, T., Donaldson, S. H., Borowitz, D., Gelfond, D., et al. (2014). Clinical Mechanism of the Cystic Fibrosis Transmembrane Conductance Regulator Potentiator Ivacaftor in G551D-Mediated Cystic Fibrosis. Am. J. Respir. Crit. Care Med. 190 (2), 175-184. doi:10.1164/ rccm.201404-0703OC

Rubin, B. K. (2002). Physiology of Airway Mucus Clearance. Respir. Care 47 (7), 761-768.

Rutland, J., and Cole, P. J. (1981). Nasal Mucociliary Clearance and Ciliary Beat Frequency in Cystic Fibrosis Compared with Sinusitis and Bronchiectasis. Thorax 36 (9), 654-658. doi:10.1136/thx.36.9.654

Schaedel, C., de Monestrol, I., Hjelte, L., Johannesson, M., Kornfält, R., Lindblad, A., et al. (2002). Predictors of Deterioration of Lung Function in Cystic Fibrosis*. Pediatr. Pulmonol. 33 (6), 483-491. doi:10.1002/ ppul. 10100

Schmid, A., Clunes, L. A., Salathe, M., Verdugo, P., Dietl, P., Davis, C. W., et al. (2011). "Nucleotide-mediated Airway Clearance," in Purinergic Regulation of Respiratory Diseases (Springer), 95-138. doi:10.1007/978-94-007-1217-1_5

Schmid, A., Baumlin, N., Ivonnet, P., Dennis, J. S., Campos, M., Krick, S., et al. (2015). Roflumilast Partially Reverses Smoke-Induced Mucociliary Dysfunction. Respir. Res. 16 (1), 135. doi:10.1186/s12931-015-0294-3

Schmid, A., Sailland, J., Novak, L., Baumlin, N., Fregien, N., and Salathe, M. (2017). Modulation of Wnt Signaling Is Essential for the Differentiation of Ciliated Epithelial Cells in Human Airways. FEBS Lett. 591 (21), 3493-3506. doi:10.1002/1873-3468.12851

Schwarzer, C., Fischer, H., Kim, E.-J., Barber, K. J., Mills, A. D., Kurth, M. J., et al. (2008). Oxidative Stress Caused by Pyocyanin Impairs CFTR Cl- Transport in Human Bronchial Epithelial Cells. Free Radic. Biol. Med. 45 (12), 1653-1662. doi:10.1016/j.freeradbiomed.2008.09.011

Sears, P. R., Yin, W.-N., and Ostrowski, L. E. (2015). Continuous Mucociliary Transport by Primary Human Airway Epithelial Cells In Vitro. Am. J. Physiol.Lung Cell Mol. Physiol. 309 (2), L99-L108. doi:10.1152/ajplung.00024.2015

Sedaghat, M. H., Shahmardan, M. M., Norouzi, M., and Heydari, M. (2016). Effect of Cilia Beat Frequency on Muco-Ciliary Clearance. J. Biomed. Phys. Eng. 6 (4), 265-278.

Seybold, Z. V., Mariassy, A. T., Stroh, D., Kim, C. S., Gazeroglu, H., and Wanner, A. (1990). Mucociliary Interaction In Vitro: Effects of Physiological and Inflammatory Stimuli. J. Appl. Physiol. 68 (4), 1421-1426. doi:10.1152/ jappl.1990.68.4.1421

Shaykhiev, R., Zuo, W.-L., Chao, I., Fukui, T., Witover, B., Brekman, A., et al. (2013). EGF Shifts Human Airway Basal Cell Fate toward a SmokingAssociated Airway Epithelial Phenotype. Proc. Natl. Acad. Sci. 110 (29), 12102-12107. doi:10.1073/pnas.1303058110

Sloane, P. A., Shastry, S., Wilhelm, A., Courville, C., Tang, L. P., Backer, K., et al. (2012). A Pharmacologic Approach to Acquired Cystic Fibrosis 
Transmembrane Conductance Regulator Dysfunction in Smoking Related Lung Disease. PloS one 7 (6), e39809. doi:10.1371/journal.pone.0039809

Smith, C. M., Djakow, J., Free, R. C., Djakow, P., Lonnen, R., Williams, G., et al. (2012). ciliaFA: a Research Tool for Automated, High-Throughput Measurement of Ciliary Beat Frequency Using Freely Available Software. Cilia 1 (1), 14. doi:10.1186/2046-2530-1-14

Snyder, R. J., Hussain, S., Tucker, C. J., Randell, S. H., and Garantziotis, S. (2017). Impaired Ciliogenesis in Differentiating Human Bronchial Epithelia Exposed to Non-cytotoxic Doses of Multi-Walled Carbon Nanotubes. Part. Fibre Toxicol. 14 (1), 1-14. doi:10.1186/s12989-017-0225-1

Song, Y., Namkung, W., Nielson, D. W., Lee, J.-W., Finkbeiner, W. E., and Verkman, A. S. (2009). Airway Surface Liquid Depth Measured in Ex Vivo Fragments of Pig and Human Trachea: Dependence on $\mathrm{Na}+$ and $\mathrm{Cl}-\mathrm{Channel}$ Function. Am. J. Physiol.-Lung Cell Mol. Physiol. 297 (6), L1131-L1140. doi:10.1152/ajplung.00085.2009

Stanek, A., Brambrink, A. M., Latorre, F., Bender, B., and Kleemann, P. P. (1998). Effects of Normobaric Oxygen on Ciliary Beat Frequency of Human Respiratory Epithelium. Br. J. Anaesth. 80 (5), 660-664. doi:10.1093/bja/80.5.660

Stubbs, J. L., Oishi, I., Izpisúa Belmonte, J. C., and Kintner, C. (2008). The Forkhead Protein Foxj1 Specifies Node-like Cilia in Xenopus and Zebrafish Embryos. Nat. Genet. 40 (12), 1454-1460. doi:10.1038/ng.267

Stubbs, J. L., Vladar, E. K., Axelrod, J. D., and Kintner, C. (2012). Multicilin Promotes Centriole Assembly and Ciliogenesis during Multiciliate Cell Differentiation. Nat. Cel Biol. 14 (2), 140-147. doi:10.1038/ncb2406

Szczesniak, R., Heltshe, S. L., Stanojevic, S., and Mayer-Hamblett, N. (2017). Use of FEV1 in Cystic Fibrosis Epidemiologic Studies and Clinical Trials: A Statistical Perspective for the Clinical Researcher. J. Cystic Fibrosis 16 (3), 318-326. doi:10.1016/j.jcf.2017.01.002

Tan, F. E., Vladar, E. K., Ma, L., Fuentealba, L. C., Hoh, R., Espinoza, F. H., et al. (2013). Myb Promotes Centriole Amplification and Later Steps of the Multiciliogenesis Program. Development 140 (20), 4277-4286. doi:10.1242/ dev.094102

Tarran, R., Grubb, B. R., Parsons, D., Picher, M., Hirsh, A. J., Davis, C. W., et al. (2001). The CF Salt Controversy: in vivo observations and therapeutic approaches. Mol. Cel. 8 (1), 149-158. doi:10.1016/s1097-2765(01)00286-6

Tarran, R. (2004). Regulation of Airway Surface Liquid Volume and Mucus Transport by Active Ion Transport. Proc. Am. Thorac. Soc. 1 (1), 42-46. doi:10.1513/pats.2306014

Thomas, B., Rutman, A., and O'Callaghan, C. (2009). Disrupted Ciliated Epithelium Shows Slower Ciliary Beat Frequency and Increased Dyskinesia. Eur. Respir. J. 34 (2), 401-404. doi:10.1183/09031936.00153308

Toskala, E., Nuutinen, J., Rautiainen, M., and Torkkeli, T. (1995). The Correlation of Mucociliary Transport and Scanning Electron Microscopy of Nasal Mucosa. Acta Oto-Laryngol. 115 (1), 61-65. doi:10.3109/ 00016489509133348

Tuggle, K. L., Birket, S. E., Cui, X., Hong, J., Warren, J., Reid, L., et al. (2014). Characterization of Defects in Ion Transport and Tissue Development in Cystic Fibrosis Transmembrane Conductance Regulator (CFTR)-Knockout Rats. PloS one 9 (3), e91253. doi:10.1371/journal.pone.0091253

Valencia-Gattas, M., Conner, G. E., and Fregien, N. L. (2016). Gefitinib, an EGFR Tyrosine Kinase Inhibitor, Prevents Smoke-Mediated Ciliated Airway Epithelial Cell Loss and Promotes Their Recovery. PloS one 11 (8), e0160216. doi:10.1371/journal.pone.0160216

Van Goor, F., Hadida, S., Grootenhuis, P. D. J., Burton, B., Cao, D., Neuberger, T., et al. (2009). Rescue of CF Airway Epithelial Cell Function In Vitro by a CFTR Potentiator, VX-770. Proc. Natl. Acad. Sci. 106 (44), 18825-18830. doi:10.1073/ pnas.0904709106

Van Goor, F., Hadida, S., Grootenhuis, P. D. J., Burton, B., Stack, J. H., Straley, K. S., et al. (2011). Correction of the F508del-CFTR Protein Processing Defect In Vitro by the Investigational Drug VX-809. Proc. Natl. Acad. Sci. 108 (46), 18843-18848. doi:10.1073/pnas.1105787108

Vij, S., Rink, J. C., Ho, H. K., Babu, D., Eitel, M., Narasimhan, V., et al. (2012). Evolutionarily Ancient Association of the FoxJ1 Transcription Factor with the Motile Ciliogenic Program. Plos Genet. 8 (11), e1003019. doi:10.1371/ journal.pgen.1003019
Wanner, A., Salathé, M., and O'Riordan, T. G. (1996). Mucociliary Clearance in the Airways. Am. J. Respir. Crit. Care Med. 154 (6 Pt 1), 1868-1902. doi:10.1164/ ajrccm.154.6.8970383

Widdicombe, J. H., and Widdicombe, J. G. (1995). Regulation of Human Airway Surface Liquid. Respiration Physiol. 99 (1), 3-12. doi:10.1016/0034-5687(94) 00095-h

Willett, C. (2019). "The Use of Adverse Outcome Pathways (AOPs) to Support Chemical Safety Decisions within the Context of Integrated Approaches to Testing and Assessment (IATA)," in ALTEX (Springer Singapore), 83-90.

Wilson, R., Pitt, T., Taylor, G., Watson, D., MacDermot, J., Sykes, D., et al. (1987). Pyocyanin and 1-hydroxyphenazine Produced by Pseudomonas aeruginosa Inhibit the Beating of Human Respiratory Cilia In Vitro. J. Clin. Invest. 79 (1), 221-229. doi:10.1172/jcil12787

Woodworth, B. A. (2015). Resveratrol Ameliorates Abnormalities of Fluid and Electrolyte Secretion in a Hypoxia-Induced Model of Acquired CFTR Deficiency. Laryngoscope 125 (S7), S1-S13. doi:10.1002/lary.25335

Xie, S., Jin, J., Xu, Z., Huang, Y., Zhang, W., Zhao, L., et al. (2019). Centrosomal Protein FOR20 Is Essential for Cilia-dependent Development in Zebrafish Embryos. FASEB J. 33 (3), 3613-3622. doi:10.1096/fj.201801235RR

Xu, X., Balsiger, R., Tyrrell, J., Boyaka, P. N., Tarran, R., and Cormet-Boyaka, E. (2015). Cigarette Smoke Exposure Reveals a Novel Role for the MEK/ERK1/2 MAPK Pathway in Regulation of CFTR. Biochim. Biophys. Acta (Bba) - Gen. Subj. 1850 (6), 1224-1232. doi:10.1016/j.bbagen.2015.02.004

Yaghi, A., and Dolovich, M. (2016). Airway Epithelial Cell Cilia and Obstructive Lung Disease. Cells 5 (4), 40. doi:10.3390/cells5040040

Yeates, D. B., Katwala, S. P., Daugird, J., Daza, A. V., and Wong, L. B. (1997). Excitatory and Inhibitory Neural Regulation of Tracheal Ciliary Beat Frequency (CBF) Activated by Ammonia Vapour and SO2. Ann. Occup. Hyg. 41, 736-744.

Yoshitsugu, M., Matsunaga, S., Hanamure, Y., Rautiainen, M., Ueno, K., Miyanohara, T., et al. (1995). Effects of Oxygen Radicals on Ciliary Motility in Cultured Human Respiratory Epithelial Cells. Auris Nasus Larynx 22 (3), 178-185. doi:10.1016/s0385-8146(12)80056-3

Yu, X., Ng, C. P., Habacher, H., and Roy, S. (2008). Foxj1 Transcription Factors Are Master Regulators of the Motile Ciliogenic Program. Nat. Genet. 40 (12), 1445-1453. doi:10.1038/ng.263

Zhang, S., Blount, A. C., McNicholas, C. M., Skinner, D. F., Chestnut, M., Kappes, J. C., et al. (2013). Resveratrol Enhances Airway Surface Liquid Depth in Sinonasal Epithelium by Increasing Cystic Fibrosis Transmembrane Conductance Regulator Open Probability. PloS one 8 (11), e81589. doi:10.1371/journal.pone.0081589

Zhang, Z., Leir, S.-H., and Harris, A. (2015). Oxidative Stress RegulatesCFTRGene Expression in Human Airway Epithelial Cells through a Distal Antioxidant Response Element. Am. J. Respir. Cel Mol. Biol. 52 (3), 387-396. doi:10.1165/ rcmb.2014-0263OC

Zhou, F., and Roy, S. (2015). SnapShot: Motile Cilia. Cell 162 (1), 224-224.e1. doi:10.1016/j.cell.2015.06.048

Conflict of Interest: KL and HY are employed by Philip Morris International (PMI). MS is employed by PETA International Science Consortium Ltd. DB is employed by British American Tobacco (Investments) Ltd. FJL is employed by Broughton Nicotine Services LLC.

Publisher's Note: All claims expressed in this article are solely those of the authors and do not necessarily represent those of their affiliated organizations, or those of the publisher, the editors and the reviewers. Any product that may be evaluated in this article, or claim that may be made by its manufacturer, is not guaranteed or endorsed by the publisher.

Copyright $\odot 2021$ Luettich, Sharma, Yepiskoposyan, Breheny and Lowe. This is an open-access article distributed under the terms of the Creative Commons Attribution License (CC BY). The use, distribution or reproduction in other forums is permitted, provided the original author(s) and the copyright owner(s) are credited and that the original publication in this journal is cited, in accordance with accepted academic practice. No use, distribution or reproduction is permitted which does not comply with these terms. 